\title{
miR-378a-3p inhibits cellular proliferation and migration in glioblastoma multiforme by targeting tetraspanin 17
}

\author{
XIAO-BING GUO $^{1 *}$, XIAO-CHAO ZHANG ${ }^{2 *}$, PENG CHEN $^{2}$, LI-MEI MA $^{1}$ and ZHI-QIANG SHEN ${ }^{2}$ \\ ${ }^{1}$ Department of Anatomy and Histology/Embryology, Faculty of Basic Medical Sciences; \\ ${ }^{2}$ School of Pharmaceutical Sciences and Yunnan Key Laboratory of Pharmacology for Natural Products, \\ Kunming Medical University, Kunming, Yunnan 650500, P.R. China
}

Received January 17, 2019; Accepted August 1, 2019

DOI: $10.3892 /$ or.2019.7283

\begin{abstract}
Glioblastoma multiforme (GBM) is the most common and aggressive brain tumor and patients with this disease tend to have poor clinical outcome. MicroRNAs (miRs) are important regulators of a number of key pathways implicated in tumor pathogenesis. Recently, the expression of miR-378 was shown to be dysregulated in several different types of cancer, including gastric cancer, colorectal cancer and oral carcinoma. Additional studies have demonstrated that miR-378 may serve as a potential therapeutic target against human breast cancer. However, the underlying mechanisms and potential targets of miR-378a-3p involved in GBM remain unknown. The aim of the present of was to determine the effects of miR-378a-3p and its potential targets. Tetraspanin 17 (TSPAN17) is involved in the neoplastic events in GBM and is a member of the tetraspanin family of proteins. The tetraspanins are involved in the regulation of cell growth, migration and invasion of several different types of cancer cell lines, and may potentially act as an oncogene associated with GBM pathology. The results of the present study showed that high miR-378a-3p and low TSPAN17 expression levels were associated with improved survival in patients with GBM. Additionally, high levels of TSPAN17 were linked to the poor prognosis of patients with GBM aged 50-60, larger tumor sizes $(\geq 5 \mathrm{~cm})$ and an advanced World Health Organization stage. TSPAN17 was identified and confirmed as a direct target of miR-378a-3p
\end{abstract}

Correspondence to: Professor Li-Mei Ma, Department of Anatomy and Histology/Embryology, Faculty of Basic Medical Sciences, Kunming Medical University, Kunming, Yunnan 650500, P.R. China E-mail: szq2019139@126.com

Professor Zhi-Qiang Shen, School of Pharmaceutical Sciences and Yunnan Key Laboratory of Pharmacology for Natural Products, Kunming Medical University, Kunming, Yunnan 650500, P.R. China E-mail:shzhq21cn@qq.com

${ }^{*}$ Contributed equally

Key words: glioblastoma multiforme, microRNA-378a-3p, tetraspanin 17 , proliferation, migration, invasion using a luciferase reporter assay in human glioma cell lines. Overexpression of miR-378a-3p in either of U87MG or MT-330 cells decreased the expression of TSPAN17, promoted apoptosis and decreased proliferation, migration and invasion. Overexpression of TSPAN17 attenuated the aforementioned effects induced by miR-378a-3p overexpression. The present study indicated that miR-378a-3p suppresses the progression of GBM by reducing TSPAN17 expression, and may thus serve as a potential therapeutic target for treating patients with GBM.

\section{Introduction}

Malignant gliomas account for $\sim 70 \%$ of all primary brain tumors diagnosed in adults (1). As the most common form of malignant glioma, glioblastoma multiforme (GBM) is the most prevalent primary brain tumor and has one of the worst prognoses of all different types of cancer (2). Several genetic and epigenetic factors have been hypothesized to serve critical roles in the etiology and prognosis of GBM; however, they remain poorly defined and insufficiently characterized (3). The identification of novel markers may be beneficial for the diagnosis and prognosis of patients with GBM.

MicroRNAs (miRs) are non-coding RNA sequences which are frequently complementary to the 3 ' untraslated region (UTR), and may completely or incompletely match the sequence of the target gene mRNA sequence. miRs degrade or inhibit translation of mRNAs and thus regulate protein expression at the post-transcriptional level (4). Bioinformatics prediction demonstrated that miRs act on an extensive range of target genes and may regulate the expression of $>30 \%$ of human genes $(4,5)$. miRs act on a wide range of target genes and participate in the fine regulation of multiple biological processes, including immunity, metabolism, differentiation, proliferation and carcinogenesis (6). Recent studies have identified miRNAs which act as tumor suppressor and oncogenes that serve important roles in tumorigenesis (7). Aberrant expression of miR-378 has been observed in various types of cancer (8-11), which suggests its potential role in human carcinogenic events (12). Li et al (13) reported that miR-378 may serve as a tumor suppressor and served an important role in inhibiting glioma tumor migration and invasion. However, the potential roles and targets of miR-378a-3p involved in GBM remain known.

The aim of the present study was to examine the potential roles of miR-378a-3p/tetraspanin 17 (TSPAN17) in the 
pathological progression of GBM. In the present study, expression of miR-378a-3p and TSPAN17 was observed in GBM tumors in patients with GBM and the human GBM cell lines, U87MG and MT-330. Luciferase reporter assay was used to determine and confirm the potential targets of miR-378a-3p and TSPAN17. The mRNA and protein expression levels of TSPAN17 were measured in the GBM cells following transfection with miR-378a-3p mimic or inhibitor. Proliferation, migration and invasion were also assessed following transfection.

\section{Materials and methods}

Ethics approval. All procedures performed in the present study involving human participants were conducted in accordance with the 1964 Declaration of Helsinki and its later amendments or comparable ethical standards. The present study was approved by The Medical Ethics Committee of Kunming Medical University (Kunming, China). GBM tumor specimens were obtained from patients at The First People's Hospital of Yunnan Province (Yunnan, China).

Preparation of tumor tissues. A total of 53 patients provided written consent to participate in the present study. The patients were registered at the clinic of The First People's Hospital of Yunnan Province between January 2010 and August 2011. All the patients recruited were undergoing surgery in the hospital for the first time and had not received anti-tumor treatment prior to surgery. The specimens were histopathologically verified as primary GBM by three senior pathologists. The primary carcinoma tissues and the matched adjacent normal tissues ( $\geq 3 \mathrm{~cm}$ away from the tumor) were collected and frozen at $-80^{\circ} \mathrm{C}$ immediately for analysis of gene or protein expression. Genetic features, including isocitrate dehydrogenase (IDH), O-6-methylguanine-DNA methyltransferase (MGMT), 1p 19q, telomerase reverse transcriptase (TERT) ATP-dependent helicase (ATRX) status, were used as genetic markers of favorable prognosis of GBM, and were used as indicators to distinguish between the subclasses of glioma, and predict outcomes in glioma with high grades $(14,15)$. To determine the expression of these markers, a DNeasy Blood \& Tissue kit (Qiagen China Co., Ltd.) was used to extract the DNA from tissue samples. The methylation status of the MGMT promoter was analyzed using a customized pyrosequencing assay, as previously described (16). A SALSA MLPA probemix (cat. no. P088-C1; MRC-Holland BV) was used for analysis of copy number of $1 p / 19 q$ as described previously (17). The presence of hotspot mutations in the IDH gene (R132 and R172), as well as the two mutation hotspots in the TERT promoter (C228T and C250T), were assessed primarily using pyrosequencing and partly using Sanger sequencing, as described previously $(18,19)$.

Cell culture and treatment. The human normal skin fibroblast HF cell line, and the GBM cell lines U87MG and MT-330, were purchased from The Cell Bank of Type Culture Collection of the Chinese Academy of Sciences. As it has been reported that the U87MG cell line has been misidentified or contaminated and this cell line is considered as a glioblastoma with unknown origin, the U87MG cell line was authenticated using STR profile detection by The Cell Bank of Type Culture Collection of the Chinese Academy of Sciences. The results showed that between the test sample and American Type Culture Collection standard data, the match ratio was $94.4 \%$; thus, the cell line was identified as a U87MG cell line. The cells were cultured in Dulbecco's Modified Eagles medium (Thermo Fisher Scientific, Inc.) at $37^{\circ} \mathrm{C}$ in a humidified atmosphere containing $5 \% \mathrm{CO}_{2}$. The medium was supplemented with $10 \%$ fetal bovine serum (Thermo Fisher Scientific, Inc.), $100 \mathrm{U} / \mathrm{ml}$ penicillin and $100 \mu \mathrm{g} / \mathrm{ml}$ streptomycin.

After culturing for five passages, the U87MG and MT-330 cells were transiently transfected with either miR-378a-3p (Esembl ID: MIMAT0000732, hsa-miR-378a-3p) mimic $(1.5 \mu 1,2.5 \mu \mathrm{M})$ /inhibitor $(3 \mu \mathrm{l}, 2.5 \mu \mathrm{M})$ or the matched negative control (NC, $2.5 \mu \mathrm{M}$ ) with Lipofectamine ${ }^{\circledR} 2000$ (Invitrogen; Thermo Fisher Scientific, Inc.). The miR-378a-3p mimic, miR-378a-3p antagomir and the matched miR NC (mimic-NC or anta-NC) were purchased from Invitrogen (Thermo Fisher Scientific, Inc.). The sequences of the miRNAs used are described as: miR-378a-3p mimic: CUGGACUUGGAG UCAGAAGG; mimic-NC: AGUGCAUGUUAUGCCUACG; miR-378a-3p antagomir: AGUUCAGGUUCUGACUCCU; anta-NC: UGGUCCGUGUAGGCCUACUA. According to the manufacturer's protocols, a final concentration of $2 \times 10^{5}$ cells were seeded into each well of a 6 -well plate and transfected for $48 \mathrm{~h}$ after which the cells were collected for further analysis.

Reverse-transcription-quantitative $(R T-q) P C R$. The expression of miR-378a-3p and TSPAN17 in human GBM cells or specimens from patients with GBM were determined using RT-qPCR. Total RNA was isolated using TRIzol ${ }^{\circledR}$ and a miRNeasy kit (Invitrogen; Thermo Fisher Scientific, Inc.) according to the manufacturer's protocol. RT-qPCR was performed using an All-in-One ${ }^{\mathrm{TM}}$ miRNA quantitative RT-PCR detection kit according to the manufacturer's protocol (GeneCopoeia, Inc.).

The miRNA primers for hsa-miR-378a-3p and U6 were purchased from Applied Biosystems (Thermo Fisher Scientific, Inc.). The thermocycling conditions were: $95^{\circ} \mathrm{C}$ For $1 \mathrm{~min}$; followed by 45 cycles of $95^{\circ} \mathrm{C}$ for $10 \mathrm{sec}, 59^{\circ} \mathrm{C}$ for $10 \mathrm{sec}$ and $72^{\circ} \mathrm{C}$ for $30 \mathrm{sec}$. The expression of miRNAs was normalized to U6. The sequences of primers are described as: U6, forward: 5'-CTCGCTTCGGCAGCACA-3', reverse: 5'-AACGCTTCA CGAATTTGCGT-3'; hsa-miR-378a-3p, forward: 5'-ACUGGA CUUGGAGUCAGAAGGC-3', reverse: 5'- GCTGTCAAC GATACGCTACGTAACG-3'.

For the detection of TSPAN17 mRNA expression, Moloney Murine Leukemia Virus Reverse Transcriptase (Takara Bio, Inc.) and a $2 X$ SYBR Green I mix (Takara Bio, Inc.) were used. The thermocycling conditions were: $95^{\circ} \mathrm{C}$ For $3 \mathrm{~min}$; followed by 39 cycles of $95^{\circ} \mathrm{C}$ for $10 \mathrm{sec}, 57^{\circ} \mathrm{C}$ for $15 \mathrm{sec}$ and $72^{\circ} \mathrm{C}$ for $30 \mathrm{sec}$; followed by $95^{\circ} \mathrm{C}$ for $10 \mathrm{sec}, 65^{\circ} \mathrm{C}$ for $5 \mathrm{sec}$ and a final $95^{\circ} \mathrm{C}$ for $10 \mathrm{sec}$. GAPDH was used as the control. The primers were synthesized by Invitrogen (Thermo Fisher Scientific, Inc.) and the sequences of the primers were: GAPDH forward, 5'-CGAGATCCCTCCAAAATCAA-3' and reverse, 5'-TTC ACACCCATGACGAACAT-3'; and TSPAN17 forward 5'-cac cagcatttccaggaacc-3' and reverse, 5'-CGCCTCCAACTACCA CAAAC-3'. The relative expression levels of the genes were determined using the $2^{-\Delta \Delta \mathrm{Cq}}$ method (20).

Bioinformatics prediction. TargetScan (http://www. targetscan.org/vert_72/), miRanda (http://miranda.org.uk) 
and PicTar (https://pictar.mdc-berlin.de), were used to predict the candidate target genes of miR-378a-3p. According to the results predicted by all three databases and the clinical data, TSPAN17 gene was selected for further analysis as a potential target involved in GBM.

Luciferase reporter assays. The target of $\mathrm{miR}-378 \mathrm{a}-3 \mathrm{p}$, TSPAN17, was validated using a luciferase reporter assay in 293T cells (The Cell Bank of Type Culture Collection of the Chinese Academy of Sciences). The wild-type (wt) or the mutant (mut) of two potential seed regions of human TSPAN17 mRNA 3'UTR, which included a potential target position for miR-378a-3p, were cloned and inserted into pLUC vector (Invitrogen; Thermo Fisher Scientific, Inc.) to generate the TSPAN17 pLUC-UTR-wt or TSPAN17 pLUC-UTR-mut vector. Briefly, 293T cells were plated into 96-well plates at $70 \%$ confluence for $24 \mathrm{~h}$ prior to transfection. A total of $25 \mathrm{ng}$ of pLUC-UTR-wt or pLUC-UTR-mutTSPAN17 was co-transfected with $50 \mathrm{nM}$ miR-378a-3p mimic/anta-NC control), or $10 \mathrm{ng}$ Renilla luciferase into $293 \mathrm{~T}$ cells using Lipofectamine ${ }^{\circledR} 2000$. Firefly luciferase activity was normalized to Renilla, and the value of firefly luciferase activity/ Renilla luciferase activity was analyzed using an iMark Fluorometer Microplate Reader (Bio-Rad, Laboratories, Inc.). A total of five independent experiments were performed in triplicate.

Knockdown of TSPAN17. Small interfering (si)RNA sequences targeting TSPAN17 and the NC (si-NC) were designed and purchased from Invitrogen (Thermo Fisher Scientific, Inc.). Lentivirus was packaged in $293 \mathrm{~T}$ cells using Lipofectamine ${ }^{\circledR} 2000$ (Invitrogen; Thermo Fisher Scientific, Inc.) for TSPAN17 gene knockdown. The GBM cells lines, U87MG and MT-330, as well as the normal HF cell line, were infected with $1 \times 10^{6}$ recombinant lentivirus-transducing units. The efficiency of siRNA knockdown was determined using RT-qPCR and western blotting. Following transfection with miR-378a-3p antagomir, the U87MG and MT-330 cells were infected with $1 \times 10^{6}$ recombinant lentivirus-transducing TSPAN17 siRNA units. A total of $24 \mathrm{~h}$ after transfection, the GBM cells were collected for further analysis. The effects of miR-378a-3p antagomir and TSPAN17 siRNA co-treated in GBM cells were also determined.

Western blotting. The protein expression levels of TSPAN17 were evaluated in the tumor tissues and different cell lines as described previously (21). Lysis buffer supplemented with protease inhibitors (cat. no. P1006, Beyotime Institute of Biotechnology) was used to extract protein from cells and tissues. A bicinchoninic acid assay (Beyotime Institute of Biotechnology) was used to quantify the concentration of the protein samples, and $35 \mathrm{mg}$ of protein extract from either the cells or tissues were used for analysis. The proteins were resolved using 15\% SDS-PAGE and transferred to nitrocellulose membranes. The membranes were incubated with anti-TSPAN17 (cat.no.PA5-69207; 1:1,000; Invitrogen; Thermo Fisher Scientific, Inc.) and anti-GAPDH (cat. no. TAB1001; 1:800; Invitrogen; Thermo Fisher Scientific, Inc.) antibodies at $4^{\circ} \mathrm{C}$ for $12 \mathrm{~h}$. The membranes were washed and incubated with the horseradish peroxidase-conjugated anti-rabbit antibody
(1:2,000; cat. no. PI-1000; Vector Laboratories, Inc.) at $37^{\circ} \mathrm{C}$ for $1 \mathrm{~h}$. The signals were visualized using enhanced chemiluminescence-based detection (BeyoECL Plus, cat. no. P0018M; Beyotime Institute of Biotechnology). The quantity of the target proteins were analyzed for each group. The blots were quantified by densitometric analysis using a ChemiDoc ${ }^{\mathrm{TM}} \mathrm{RS}+$ imaging system and Image $\mathrm{Lab}^{\mathrm{TM}}$ software v5.2.1 (Bio-Rad, Laboratories, Inc.).

MTT assay. Briefly, $1 \times 10^{5}$ cells were plated into 96-well culture plates in $200 \mu \mathrm{l}$ culture medium per well. After $48 \mathrm{~h}$ of culture with the aforementioned treatments, $20 \mu 15 \mathrm{mg} / \mathrm{ml}$ MTT was added to each well and incubated at $37^{\circ} \mathrm{C}$ for $4 \mathrm{~h}$. The medium was gently aspirated and $150 \mu \mathrm{l}$ of DMSO was added to each well to solubilize the formazan crystals. The absorbance of each sample was immediately measured using a microplate reader (Multiskan Mk3; Thermo Fisher Scientific, Inc.) at $570 \mathrm{~nm}$.

Apoptosis assay. An Annexin V-fluorescein isothiocyanate-flow cytometry assay kit (Beijing 4A Biotech Co.) was used to detect the apoptotic rate in the U87MG and MT-330 cells following transfection with the vectors, as described previously $(22,23)$. The kit was used according to the manufacturer's protocols. For flow cytometry, a FACScan flow cytometer (BD Immunocytometry Systems) was used and the data were analyzed using Cellquest software 10.6.4 version (BD Immunocytometry Systems). The apoptotic rate is indicated as the percentages of cells staining with both Annexin $\mathrm{V}^{+} / \mathrm{PI}^{-}$(early apoptosis) and AnnexinV ${ }^{+} / \mathrm{PI}^{+}$ (late apoptosis). The calculated formula: apoptotic rate $=$ the percentages of (Q1-UR quadrant + Q1-LR quadrant).

Migration and invasion assays. Cells $\left(1 \times 10^{5}\right)$ in serum-free medium were placed into the upper chamber of a Transwell insert (BD Bioscience) with or without Matrigel ${ }^{\circledR}$. After $48 \mathrm{~h}$ of incubation, cells remaining in the upper chamber or on the upper membrane were carefully removed. Cells adhering to the lower membrane were stained with $0.1 \%$ crystal violet for 20 min and fixed with $20 \%$ methanol at room temperature for $30 \mathrm{sec}$, imaged, and counted using an IBX3 inverted microscope (Olympus Corporation) (24). Under x200 magnification, five random fields of view were analyzed.

Statistical analysis. Data are presented as the mean \pm standard deviation. SPSS version 21.0 (IBM Corp.) was used for analysis. Based on the median expression levels of miR-378a-3p or TSPAN17, the enrolled patients were divided into two cohorts, high and low expression (25). 5-year overall survival curves of GBM patients with different expressional levels of miR-378a-3p or TSPAN17 were analyzed by the Kaplan-Meier method and compared using the log-rank test. A $\chi^{2}$ test was used to compare the test the significant differences in observed variables. Pearson correlation analysis was performed to analysis the correlation between miR-378a-3p expression and TSPAN17 level in patients with GBM. Multivariate logistical regression analysis was performed to evaluate the association between TSPAN17 gene expression levels with clinicopathologic characteristics of GBM. A paired Student's t-test was used to compare the expression levels of TSPAN17 
A

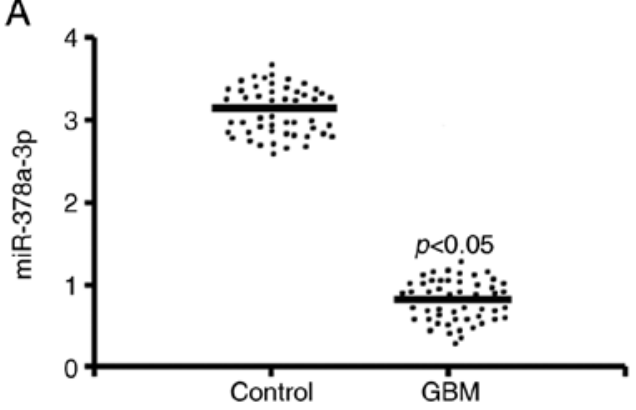

C

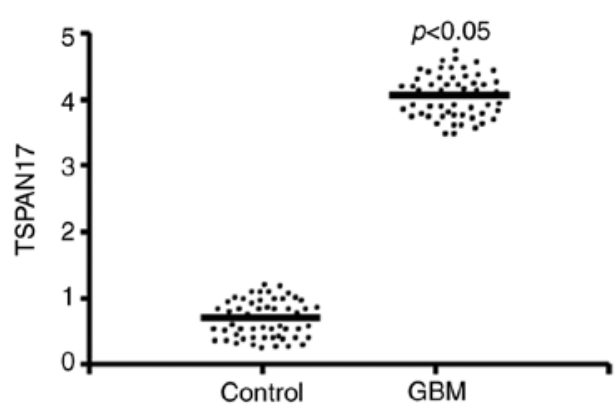

E

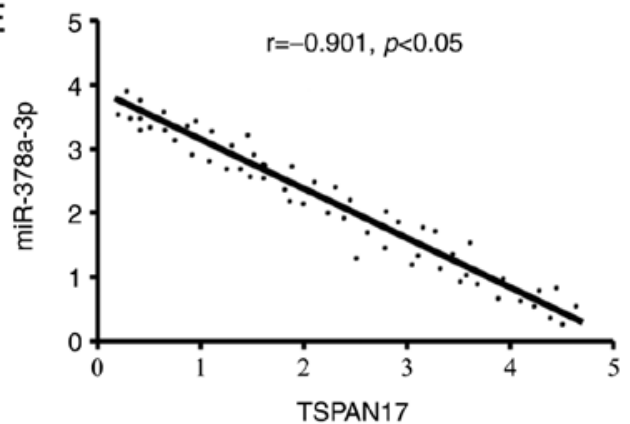

B

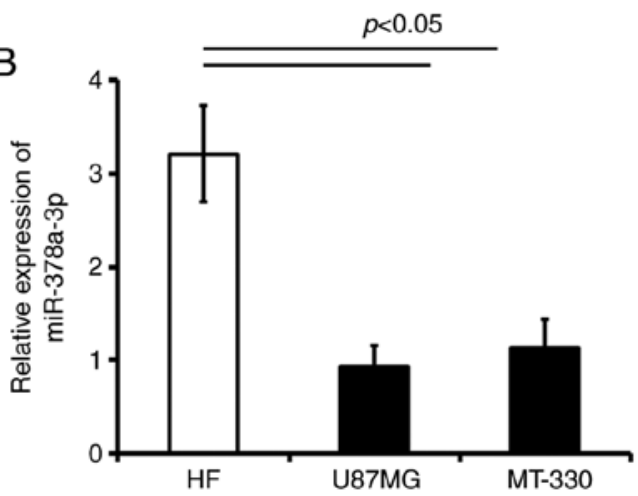

D

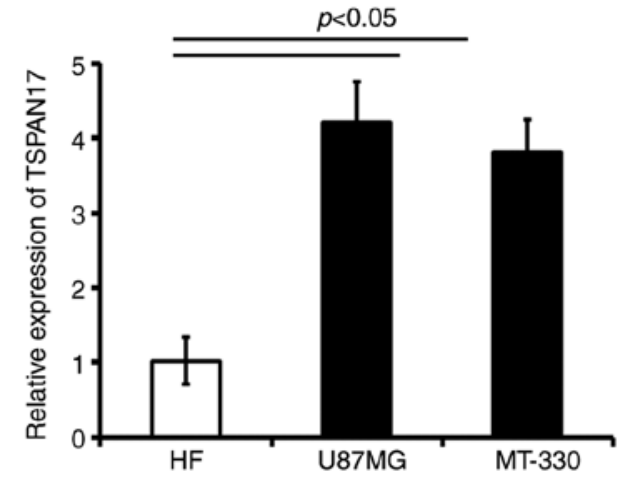

$\mathrm{F}$

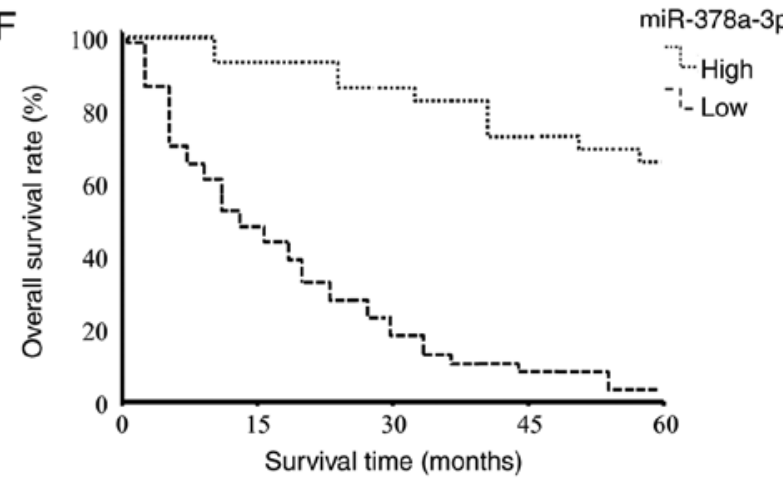

G

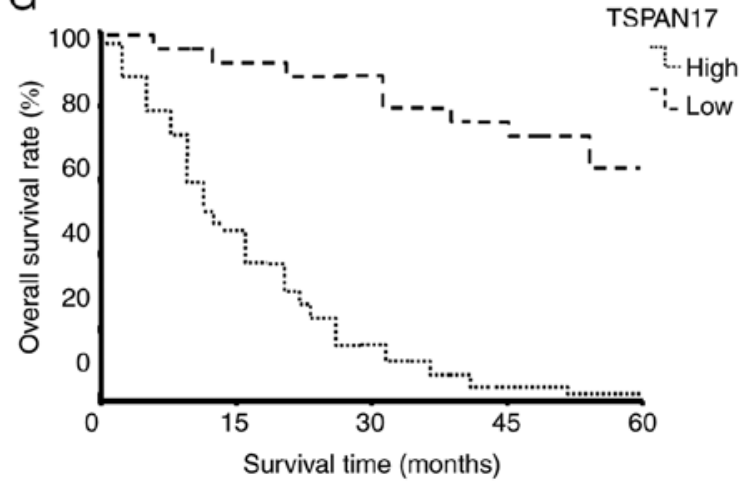

Figure 1. Abnormal expression of miR-378a-3p and TSPAN17 are associated with GBM. (A) Relative expression of miR-378a-3p in normal adjacent tissues and tumors from GBM patients were detected by RT-qPCR ( $\mathrm{n}=53$ ). (B) Relative expression of miR-378a-3p in normal human HF, U87MG and MT-330 cells. (C) Relative expression of TSPAN17 in control and tumor samples from GBM patients were detected by RT-qPCR (n=53). (D) Relative expression of TSPAN17 in normal human HF, U87MG and MT-330 cells. (E) Correlation between miR-378a-3p and TSPAN17 expression levels in tumor of GBM patients $(\mathrm{n}=53)$. (F) GBM patients with high expression of miR-378a-3p exhibited improved survival rate than those with low expression (log-rank test: $\chi^{2}=13.53$, $\mathrm{P}=0.00048) .(\mathrm{G})$ Patients with low TSPAN17 expression levels were associated with higher survival rates than those with high TSPAN17 expression (log-rank test: $\left.\chi^{2}=17.93, \mathrm{P}=0.00032\right)(\mathrm{n}=53)$. Data are presented as the mean \pm standard deviation. Five independent experiments were performed in triplicate $(\mathrm{n}=5)$. Control, normal adjacent tissues; GBM, glioblastoma multiforme; miR, microRNA; RT-qPCR, reverse transcription-quantitative polymerase chain reaction; TSPAN17, tetraspanin 17.

and miR-378a-3p between GBM and the matched adjacent normal groups. The statistical significance of RNA expression, apoptotic rates, cell activity, migration and invasion among cells in the different treatment groups were analyzed using a 
Table I. TSPAN17 levels are associated with clinicopathologic and genetic features of patients with glioblastoma multiforme.

\begin{tabular}{|c|c|c|c|c|}
\hline \multirow[b]{2}{*}{ Clinicopathological characteristics } & \multicolumn{2}{|c|}{ TSPAN17 levels (mRNA) } & \multirow[b]{2}{*}{$r_{s}$} & \multirow[b]{2}{*}{ P-value } \\
\hline & Low level $n=12$ & High level $n=41$ & & \\
\hline Ages $\left(\right.$ years) ${ }^{b}$ & & & 0.313 & $0.019^{\mathrm{a}}$ \\
\hline $40-49$ & 4 & 7 & & \\
\hline $50-60$ & 5 & 25 & & \\
\hline$>60$ & 3 & 9 & & \\
\hline Sex & & & 0.114 & 0.31 \\
\hline Male & 7 & 20 & & \\
\hline Female & 5 & 21 & & \\
\hline Tumor size $(\mathrm{cm})$ & & & 0.632 & $0.0009^{\mathrm{a}}$ \\
\hline$<5 \mathrm{~cm}$ & 7 & 9 & & \\
\hline$\geq 5 \mathrm{~cm}$ & 5 & 32 & & \\
\hline WHO grade & & & 0.554 & $0.0013^{\mathrm{a}}$ \\
\hline I-II & 6 & 7 & & \\
\hline III & 5 & 10 & & \\
\hline IV & 1 & 24 & & \\
\hline$I D H$ status & & & 0.701 & $0.001^{\mathrm{a}}$ \\
\hline Wild-type & 10 & 33 & & \\
\hline Mutant & 2 & 8 & & \\
\hline$M G M T$ status & & & 0.254 & $0.045^{\mathrm{a}}$ \\
\hline Methylated & 7 & 18 & & \\
\hline Unmethylated & 5 & 23 & & \\
\hline $1 p 19 q$ status & & & 0.198 & 0.122 \\
\hline Non-codeletion & 4 & 20 & & \\
\hline Codeletion & 8 & 21 & & \\
\hline$T E R T$ & & & 0.107 & 0.33 \\
\hline Wild-type & 6 & 19 & & \\
\hline Mutant & 6 & 22 & & \\
\hline$A T R X$ & & & 0.821 & $<0.001^{\mathrm{a}}$ \\
\hline Wild-type & 5 & 3 & & \\
\hline Mutant & 7 & 38 & & \\
\hline
\end{tabular}

Values in bold indicate $\mathrm{P}<0.05 .{ }^{\mathrm{a}} \mathrm{P}<0.05 .{ }^{\mathrm{b}} \mathrm{The}$ age classification of patients was according to Zhang et al (46). ATRX, ATP-dependent helicase; IDH, isocitrate dehydrogenase; MGMT, O-6-methylguanine-DNA methyltransferase; TERT, telomerase reverse transcriptase; TSPAN17, tetraspanin 17; WHO, World Health Organization.

one-way ANOVA. The Least Significant Difference post-hoc test was used to obtain individual P-values following ANOVA. $\mathrm{P}<0.05$ was considered to indicate a statistically significant difference unless otherwise indicated.

\section{Results}

Decreased expression of miR-378a-3p and increased expression of Tspan17 are associated with GBM. The expression levels of miR-378a-3p and its potential target gene TSPAN17 were detected in both the tumor tissues of patients with GBM and GBM cell lines using RT-qPCR. The results showed that the expression of miR-378a-3p in GBM tissues was significantly lower compared with the adjacent non-neoplastic tissues $(\mathrm{P}=0.00021$; Fig. 1A). Similarly, the expression of miR-378a-3p was significantly decreased in U87MG and MT-330 cells compared with HF cells $(\mathrm{P}=0.00017$, $\mathrm{P}=0.00028$; Fig. 1B).

Conversely, the mRNA expression levels of TSPAN17 were significantly increased in the tumor tissues compared with the control $(\mathrm{P}=0.00008$; Fig. $1 \mathrm{C})$, which was also observed in the GBM cells compared with the HF cells $(\mathrm{P}=0.00007$, $\mathrm{P}=0.00011$; Fig. 1D).

Correlation analysis showed that decreased miR-378a-3p expression was inversely correlated with TSPAN17 expression in patients with GBM ( $\mathrm{r}=-0.901, \mathrm{P}<0.05$; Fig. 1E).

The 5-year overall survival (OS) analysis revealed that patients with GBM with high expression of miR-378a-3p (cut-off level 0.49 ; $>0.49$ high expression) demonstrated a higher rate OS compared with patients with low expression 
Table II. Multivariate analysis of miR-378a-3p and Tspan17 levels in patients with glioblastoma multiforme.

\begin{tabular}{|c|c|c|c|c|c|c|}
\hline & \multicolumn{2}{|c|}{ miR-378a-3p expression } & \multirow[b]{2}{*}{$\begin{array}{c}\text { Adjusted } \\
\text { OR (95\% CI) }\end{array}$} & \multicolumn{2}{|c|}{ TSPAN17 expression } & \multirow[b]{2}{*}{$\begin{array}{c}\text { Adjusted } \\
\text { OR }(95 \% \text { CI) }\end{array}$} \\
\hline & $\begin{array}{c}\text { Low level } \\
(\leq \text { median) } \mathrm{n}(\%)\end{array}$ & $\begin{array}{c}\text { High level } \\
(>\text { median) } \mathrm{n}(\%)\end{array}$ & & $\begin{array}{c}\text { Low level } \\
\text { ( } \leq \text { median) n }(\%)\end{array}$ & $\begin{array}{l}\text { High level } \\
\text { n }(\%)\end{array}$ & \\
\hline \multicolumn{7}{|c|}{ WHO grade } \\
\hline I-II & $2(3.7)$ & $5(9.4)$ & $2.24 \quad(1.54-4.02)$ & $6(11.3)$ & $7(13.2)$ & $1.58 \quad(0.98-4.21)$ \\
\hline III & $23(43.4)$ & $2(3.7)$ & $16.19(12.36-28.21)$ & $5 \quad(9.4)$ & $10(18.8)$ & $14.11(9.45-29.2)$ \\
\hline IV & $21(39.6)$ & $0 \quad(0)$ & $21.15(12.31-31.58)$ & $1 \quad(1.8)$ & $24(45.2)$ & $10.34(5.01-23.95)$ \\
\hline \multicolumn{7}{|c|}{ Tumor size $(\mathrm{cm})$} \\
\hline$<5$ & $12(22.6)$ & $6(11.3)$ & $1.82(1.33-5.01)$ & $7(13.2)$ & $22(41.5)$ & $1.23 \quad(0.73-6.49)$ \\
\hline$\geq 5$ & $34(64.1)$ & $1(1.8)$ & $42.03(28.93-57.38)$ & $5 \quad(9.4)$ & $19(35.8)$ & $1.49 \quad(0.87-3.97)$ \\
\hline
\end{tabular}

Values in bold indicate $\mathrm{P}<0.05 .95 \% \mathrm{CI}$, confidence interval, miR, microRNA; OR, odds ratio; TSPAN17, tetraspanin 17.

( $\leq 0.49$, low expression $)\left(\chi^{2}=13.53, \mathrm{P}=0.00048\right.$; Fig. $\left.1 \mathrm{~F}\right)$. The OS rate of patients with low levels of TSPAN17 (cut-off level 3.78; $\leq 3.78$, low expression) in tumors was higher compared with high levels of TSPAN17 $\left(>3.78\right.$, high expression) $\left(\chi^{2}=17.93\right.$, $\mathrm{P}=0.00032$; Fig. 1G).

The association between expression of TSPAN17 and the clinicopathological characteristics of patients were determined using the GBM tissues. The results showed that high expression of TSPAN17 was significantly associated with age (50-60 years old; $\left.r_{s}=0.313, P=0.019\right)$, tumor size $\left(r_{s}=0.632\right.$, $\mathrm{P}=0.00009$ ), World Health Organization (WHO) grade $\left(r_{\mathrm{s}}=0.554, \mathrm{P}=0.0013\right)$, IDH status $\left(\mathrm{r}_{\mathrm{s}}=0.701, \mathrm{P}<0.001\right)$, MGMT status $\left(r_{s}=0.254, P=0.045\right)$ and ATRX status $\left(r_{s}=0.821\right.$, $\mathrm{P}<0.001$; Table I). The TERT promoter mutations, coinciding with IDH1/2 mutations and 1p/19q codeletion were the most common genotypes detected in the oligodendrogliomas, while a combination genotype of IDH-wt and TERT promoter mutation were always present in patients with GBM (14). ATRX mutations, a molecular marker for astrocytic tumors, combined with p53 mutations can predict the prognosis of patients with glioma (26). The results of the present study indicated that the high expression of TSPAN17 was significantly associated with a poor survival rate, larger tumor and higher WHO grade of glioma, as well as the aforementioned genetic markers. Combined with the clinicopathologic features and common genotypes present, high expression of TSPAN17 in carcinomas may be used as a molecular indicator of poor prognosis. The multivariate analysis of miR-378a-3p and TSPAN17 levels in patients with GBM were also analyzed (Table II). The data suggested that decreased miR-378a-3p and increased TSPAN17 levels were associated with GBM.

Validating TSPAN17 as a target gene of miR-378a-3p. The expression levels of miR-378a-3p were measured in cells transfected with miR-378a-3p mimics or inhibitor. The results demonstrated that transfection with miR-378a-3p mimics significantly upregulated the expression levels of miR-378a-3p in U87MG cells (mimic, 2.08 \pm 0.15 ; mimic-NC, 0.53 \pm 0.07 ; $\mathrm{P}<0.05$ ) and MT-330 cells (mimic, 1.98 \pm 0.21 ; mimic-NC, $0.61 \pm 0.08 ; \mathrm{P}<0.05)$ compared with the control. Following miR-378a-3p antagomir transfection, miR-378a-3p expression was significantly decreased in U87MG (antagomir, 0.12 \pm 0.01 ; anta-NC, $0.56 \pm 0.02 ; \mathrm{P}<0.05)$ and MT-330 cells compared with the control (antagomir, 0.22 \pm 0.01 ; anta-NC, 0.59 \pm 0.01 ; $\mathrm{P}<0.05$ ) (Fig. 2).

It was determined that miR-378a-3p has two conserved putative binding sites for TSPAN17 mRNA on the 3'UTR at positions 179-186 and 891-897 (Fig. 3A). Transfection of TSPAN17 pLUC-UTR-wt in combination with miR-378a-3p mimic significantly reduced the luciferase activity compared with the corresponding control; this reduction of luciferase activity was not observed in cells transfected with TSPAN17 pLUC-UTR-mut vector. Furthermore, mutation of the putative miR-378a-3p binding sites abrogated the suppressive effects of miR-378a-3p mimic on the luciferase activity in 293T cells (Fig. 3B).

Transfection with miR-378a-3p mimic significantly reduced the expression of TSPAN17 in the GBM cell lines compared with miR-NC $(\mathrm{P}<0.05)$. On the contrary, transfection with miR-378a-3p antagomir increased the expression of TSPAN17 mRNA levels in GBM cells compared with anta-NC transfected cells $(\mathrm{P}<0.05$; Fig. $3 \mathrm{C}$ and $\mathrm{D})$. Therefore, the results suggested that miR-378a-3p directly binds to TSPAN17 3' UTR and inhibited its expression.

TSPAN17 knockdown. The U87MG and MT-330 cells, as well as the control HF cells were stably transfected with TSPAN17-siRNA or si-NC lentiviral vector. The data showed that siRNA significantly reduced $m$ RNA and protein expression levels of TSPAN17 (normalized by si-NC control) in U87MG, MT-330 and HF cells (Fig. 4). The mRNA levels of TSPAN17 were significantly reduced following TSPAN17-siRNA transfection in U87MG $(0.11 \pm 0.001$ vs. si-NC; $\mathrm{P}<0.05)$, MT-330 $(0.13 \pm 0.006$ vs. si-NC; $\mathrm{P}<0.05)$ and $\mathrm{HF}(0.08 \pm 0.001$ vs. si-NC; $\mathrm{P}<0.05)$ cells. In accordance with the $\mathrm{RT}-\mathrm{qPCR}$ results, TSPAN17 protein levels were significantly lower in TSPAN17 siRNA- lentiviral transduced cells compared with the si-NC control of U87MG $(0.08 \pm 0.009)$, MT-330 $(0.07 \pm 0.005)$ and HF $(0.2 \pm 0.003)$ cells (vs. si-NC, $\mathrm{P}<0.05$; Fig. $4 \mathrm{~A}-\mathrm{C}$ ).

Additionally, the effects of miR-378a-3p antagomir and TSPAN17 siRNA co-treated were confirmed by RT-qPCR and western blotting (Fig. $2 \mathrm{~B}$ and $\mathrm{C}$ ). Following co-treatment with 
A
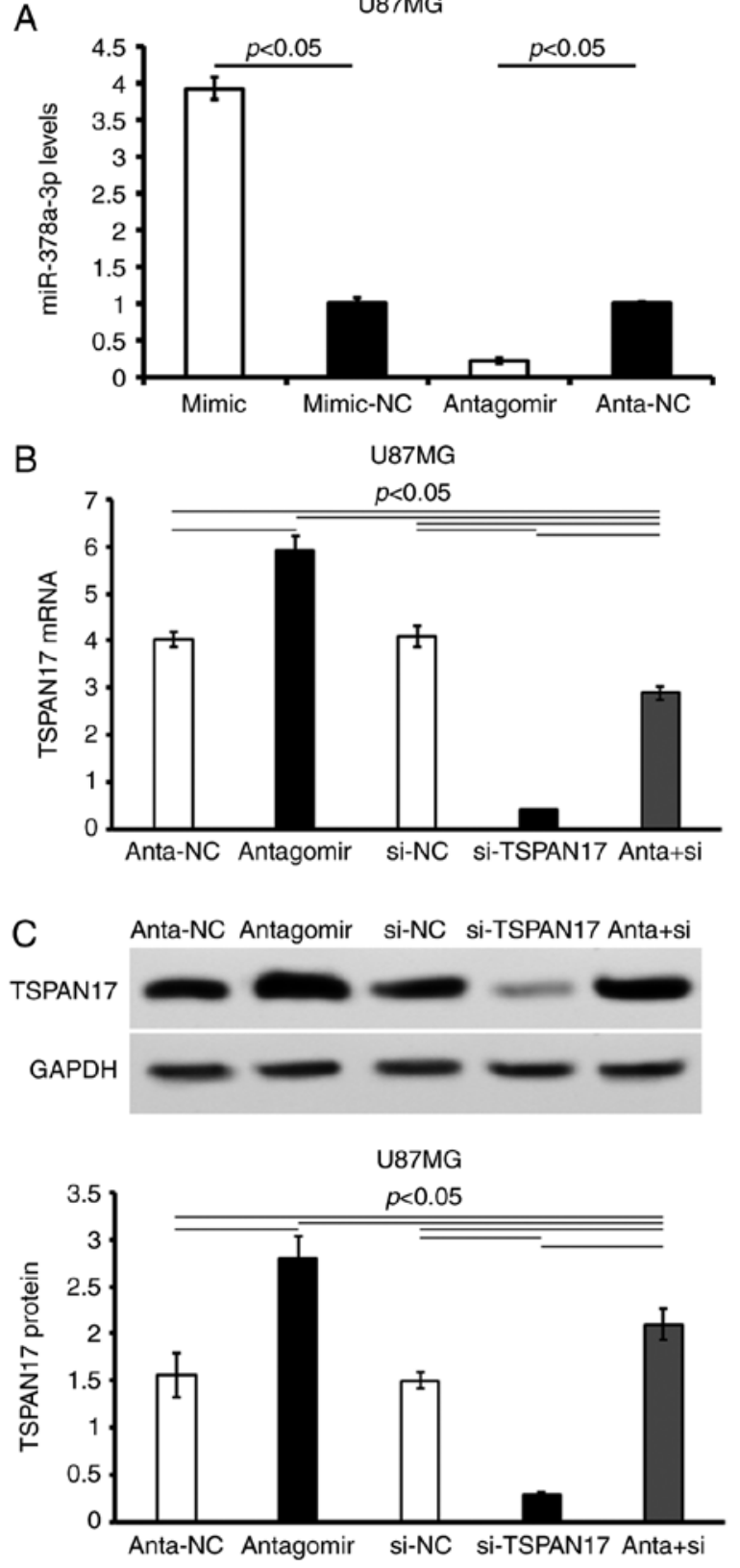
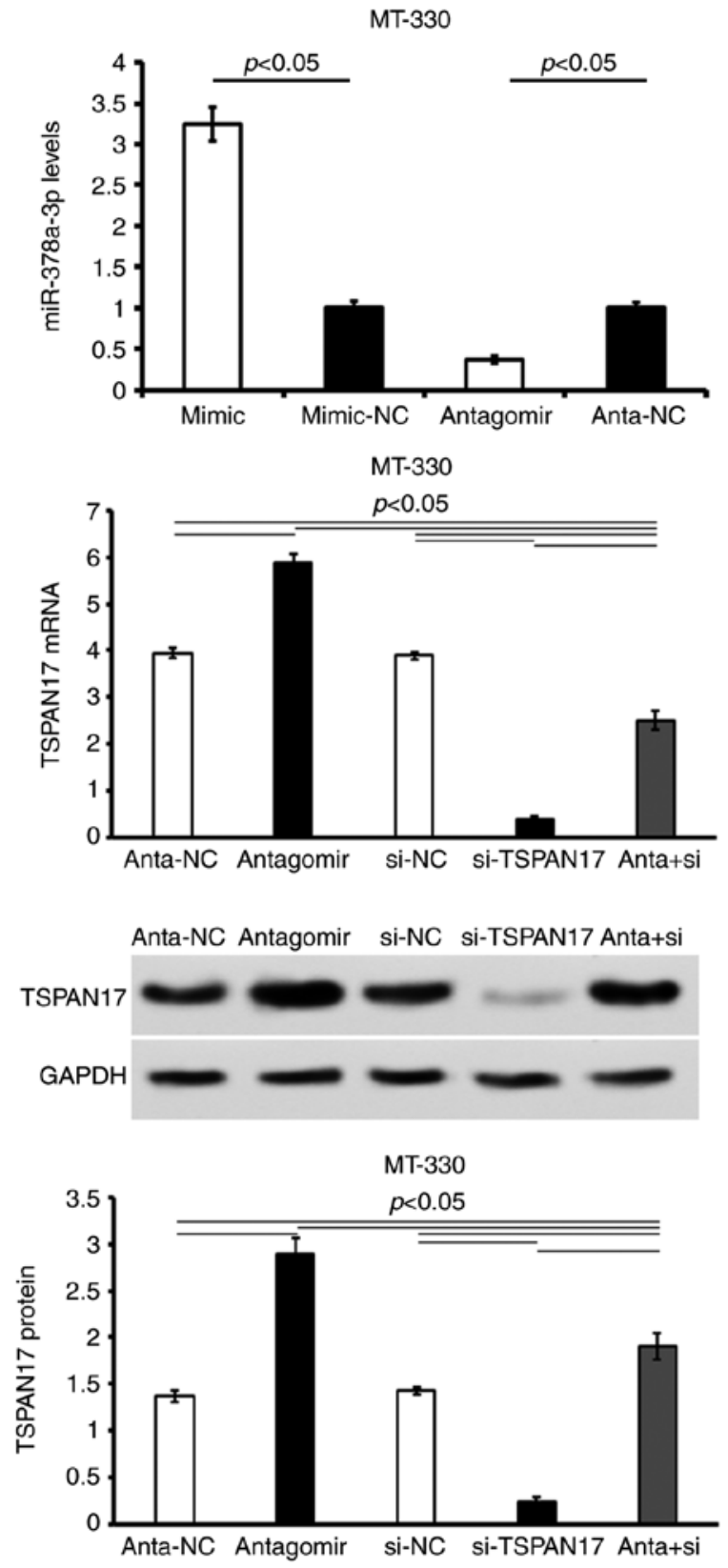

Figure 2. Validation of transfection efficiency of mimic or antagomir on miR-378a-3p expression. (A) Relative expression of miR-378a-3p in U87MG and MT-330 cells treated with miR-378a-3p mimic or antagomir. The relative expression levels of miR-378a-3p were normalized with the matched NC. (B) Relative expression of TSPAN17 mRNA in U87MG and MT-330 cells treated with both miR-378a-3p antagomir and si-TSPAN17. (C) Relative expression of TSPAN17 protein in U87MG and MT-330 cells treated with both miR-378a-3p antagomir and si-TSPAN17. Data are presented as the mean \pm standard deviation. All the data are representative of five independent experiments $(n=5)$. miR, microRNA; mimic, miR-378a-3p mimic; mimic-NC, miR-378a-3p mimic negative control; antagomir, miR-378a-3p antagomir; anta-NC, miR-378a-3p antagomir negative control; si-NC, siRNA negative control; si-TSPAN17, TSPAN17 siRNA; anta + si, miR-378a-3p antagomir + TSPAN17 siRNA.

miR-378a-3p antagomir and TSPAN17 siRNA, the levels of TSPAN17 mRNA were significantly increased in U87MG (anta + si, 2.89 \pm 0.14 vs. antagomir, 5.93 $\pm 0.24, \mathrm{P}<0.05$; vs. si-TSPAN17, 0.4 $\pm 0.02, \mathrm{P}<0.05$; vs. anta-NC, 4.02 $\pm 0.16, \mathrm{P}<0.05$; vs. si-NC, $4.1 \pm 0.22, \mathrm{P}<0.05)$ and $\mathrm{MT}-330$ cells $($ anta $+\mathrm{si}$, $2.51 \pm 0.21$ vs. antagomir, 5.1 $\pm 0.19, \mathrm{P}<0.05$; vs. si-TSPAN17, $0.38 \pm 0.06, \mathrm{P}<0.05$; vs. anta-NC, $3.94 \pm 0.11, \mathrm{P}<0.05$; vs si-NC, $3.89 \pm 0.09, \mathrm{P}<0.05$ ) (Fig. 2B). The results of western blotting were consistent with that of the RT-qPCR. TSPAN17 protein levels in the con-transfected U87MG (anta + si, $2.1 \pm 0.16$ vs. antagomir, 2.8 $\pm 0.24, \mathrm{P}<0.05$; vs si-TSPAN17, 0.28 \pm 0.03 ; $\mathrm{P}<0.05$; vs anta-NC, $1.56 \pm 0.23$. $\mathrm{P}<0.05$; vs si-NC, $1.51 \pm 0.09$,
$\mathrm{P}<0.05$ ) and MT-330 (anta+si, 1.9 \pm 0.14 ) (vs antagomir, $2.9 \pm 0.17 ; \mathrm{P}<0.05 ;$ vs si-TSPAN17, 0.23 $\pm 0.05 ; \mathrm{P}<0.05$; vs anta-NC, 1.37 \pm 0.06 . $\mathrm{P}<0.05$; vs si-NC, $1.43 \pm 0.04, \mathrm{P}<0.05)$ cells were restored in part (Fig. 2C). However, the expressions of TSPAN17 didn't return to the level of negative control ( $\mathrm{P}<0.05$, Fig. 2B and C). Effects of miR-378a-3p/TSPAN17 on proliferation and apoptosis. Transfection with miR-378a-3p mimic or TSPAN17 siRNA significantly decreased cell proliferation and increased the apoptotic rate in U87MG $(\mathrm{P}<0.05$; Fig. 5) and MT-330 cells, compared with the corresponding controls $(\mathrm{P}<0.05$; Fig. 6). Transfection with miR-378a-3p antagomir resulted in a significant increase in cell proliferation 
A

\begin{tabular}{|c|c|c|}
\hline \multirow{2}{*}{$\begin{array}{c}\text { Putative } \\
\text { binding } \\
\text { position }\end{array}$} & Wide type (wt) & Mutant (mut) \\
\cline { 2 - 3 } & 3' UTR of TSPAN17 gene \\
\hline \multirow{3}{*}{$179-186$} & $5^{\prime}$...UAGAUUUCACAUAAAAGUCCAGA... & $5^{\prime}$...UAGAUUUCACAUAAAUCAGGUCA... \\
\cline { 2 - 3 } & $\begin{array}{c}\text { 3' CGGAGACUGAGGUUCAGGUCA } \\
\text { has-miR-378a-3p }\end{array}$ & $\begin{array}{c}3^{\prime} \text { CGGAAGACUGAGGUUCAGGUCA } \\
\text { has-miR-378a-3p }\end{array}$ \\
\hline \multirow{3}{*}{$891-897$} & $5^{\prime}$...CCCCUCCCUGGGCUCGUCCAGAG... & $5^{\prime}$...CCCCUCCCUGGGCUCCAGGUCAG... \\
\cline { 2 - 3 } & $\begin{array}{c}\text { 3' CGGAAGACUGAGGUUCAGGUCA } \\
\text { has-miR-378a-3p }\end{array}$ & $\begin{array}{c}\text { 3' CGGAAGACUGAGGUUCAGGUCA } \\
\text { has-miR-378a-3p }\end{array}$ \\
\hline
\end{tabular}

Position 179-186

Position 891-897
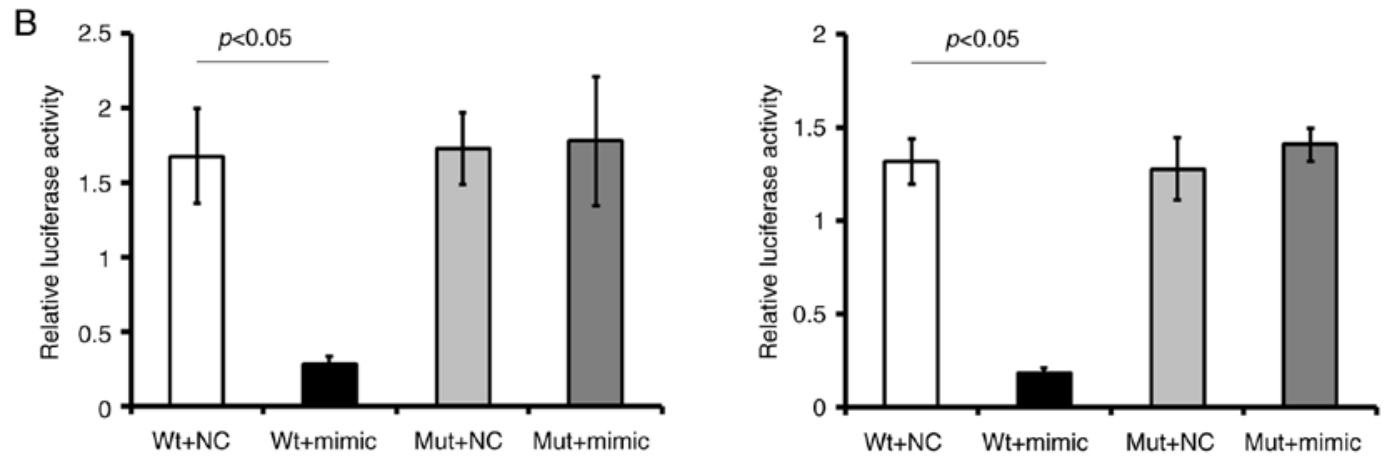

C
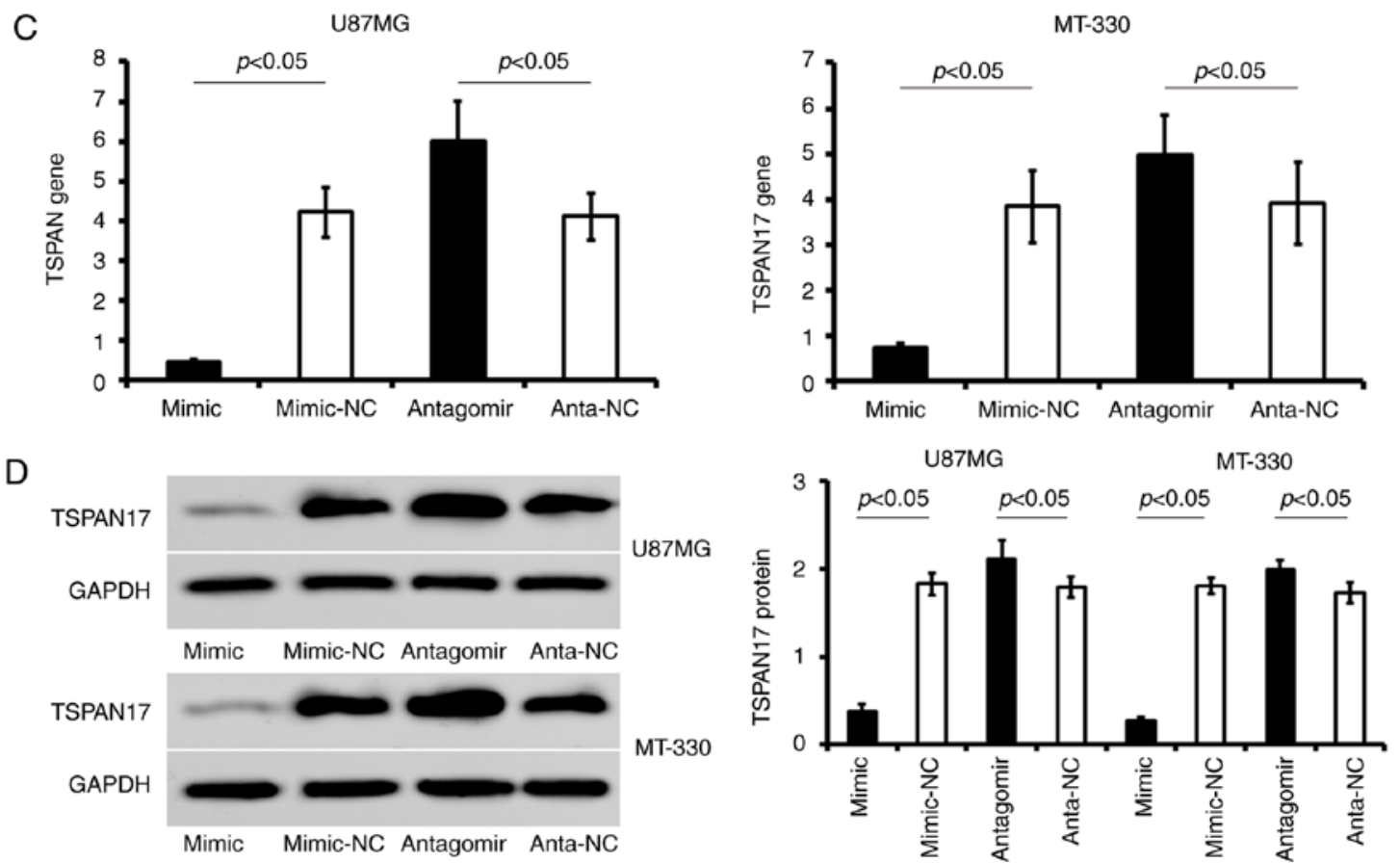

Figure 3. TSPAN17 is a potential target gene for miR-378a-3p. (A) Putative binding sites directly regulated by miR-378a-3p and the pattern of mutating the two binding sites (179-186 and 891-897) within TSPAN17 3'UTR. (B) Detection of the relative luciferase activity of miR-378a-3p mimic co-transfected with TSPAN17 3'UTR-wt or -mut by dual-luciferase reporter assay. (C) relative expression of TSPAN17 gene in U87MG and MT-330 cells treated with miR-378a-3p mimic or antagomir. (D) Representative blots for TSPAN17 and GAPDH, as well as the relative expression of TSPAN17 protein in U87MG and MT-330 cells treated with miR-378a-3p mimic or antagomir. Data are represented as mean \pm standard deviation. All the data are representative of five independent experiments $(\mathrm{n}=5)$. miR, microRNA; mimic, miR-378a-3p mimic; mimic-NC, miR-378a-3p mimic negative control; antagomir, miR-378a-3p antagomir; anta-NC, miR-378a-3p antagomir negative control; mut, mutant; TSPAN17, tetraspanin 17; UTR, untranslated region; wt, wild-type.

and reduced apoptosis in both U87MG (P<0.05; Fig. 5) and MT-330 cells $(\mathrm{P}<0.05$; Fig. 6$)$ compared with the corresponding controls. Co-treatment with miR-378a-3p antagomir and TSPAN17 siRNA partially attenuated these effects induced by miR-378a-3p antagomir.
Migration and invasion. The migration assay revealed that there were significantly fewer cells stained with crystal violet in the miR-378a-3p mimic-transfected cells, compared with the matched NC transfected cells. Additionally, transfection with TSPAN17 siRNA significantly decreased migration and 
A

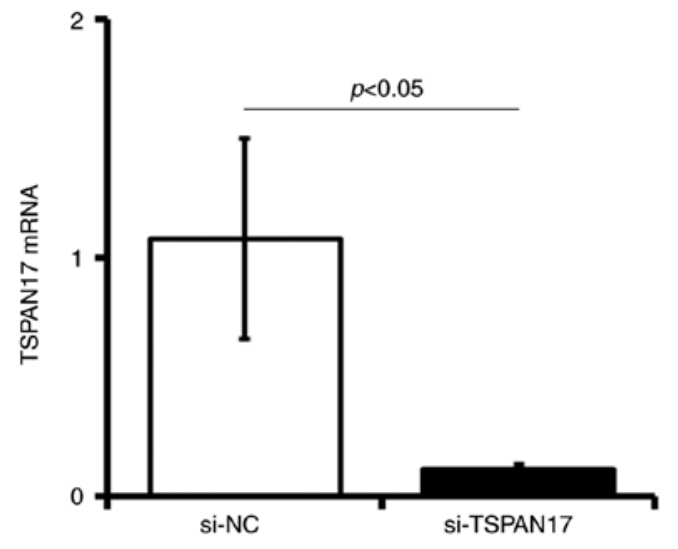

U87MG

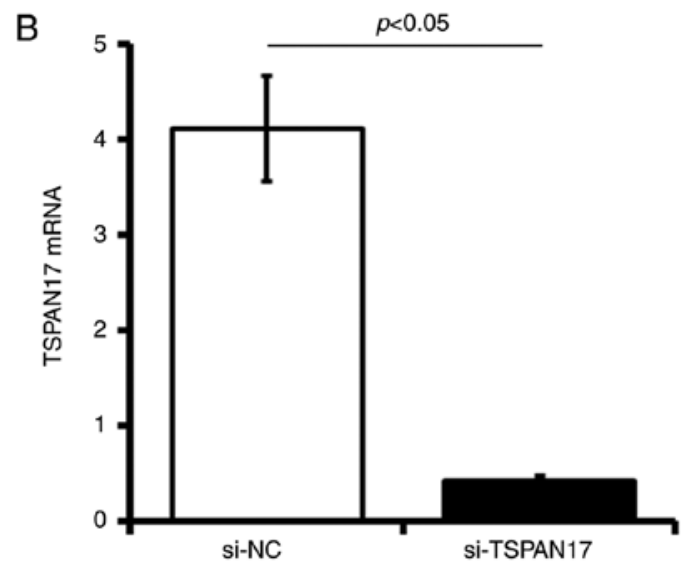

C

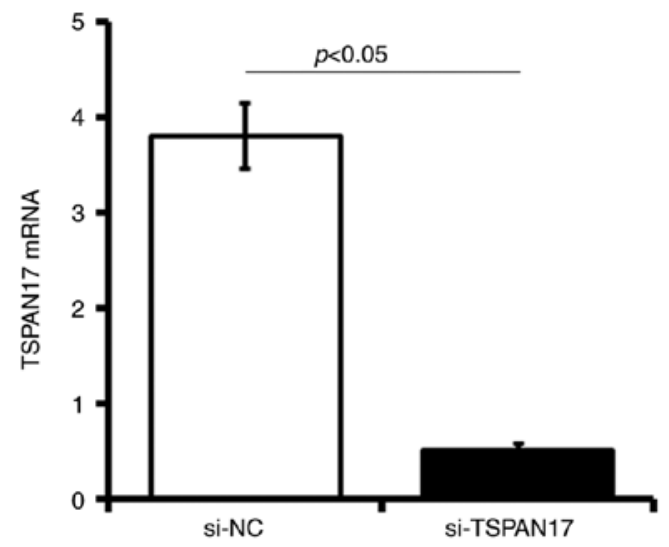

MT-330
$\mathrm{HF}$
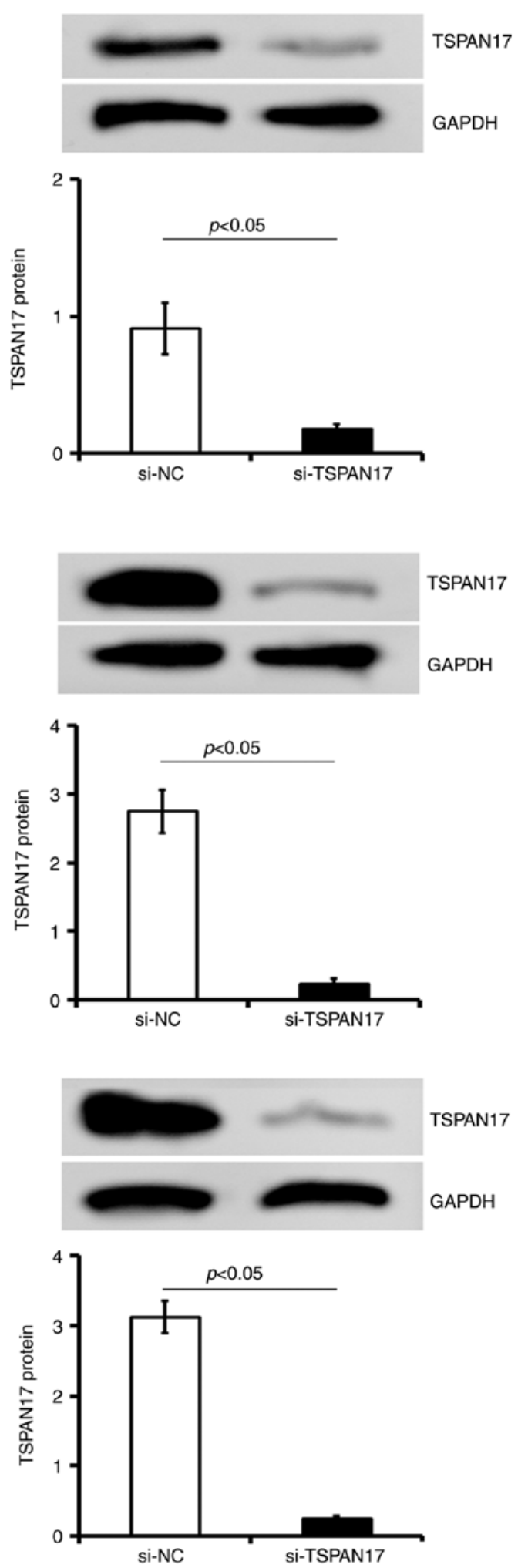

Figure 4. si-TSPAN17 decreases TSPAN17 expression. TSAPAN17 mRNA and protein levels were detected by reverse transcription-quantitative polymerase chain reaction and western blotting in (A) HF, (B) U87MG and (C) MT-330 cells following si-TSPAN17 transfection, respectively. Data are presented as the mean \pm standard deviation. All the data are representative of five independent experiments $(\mathrm{n}=5)$. si, small interfering RNA; NC, negative control; TSPAN17, tetraspanin 17 .

invasion in both U87MG (Fig. 7) and MT-330 (Fig. 8) cells compared with the respective NC cells $(\mathrm{P}<0.05)$. Furthermore, co-treatment with miR-378a-3p antagomir and TSPAN17 siRNA attenuated the effects on migration and invasion induced by miR-378a-3p antagomir transfection (Figs. 7 and 8). The results showed that overexpression of miR-378a-3p significantly inhibited migration and invasion in GBM cells by targeting TSPAN17. 
A

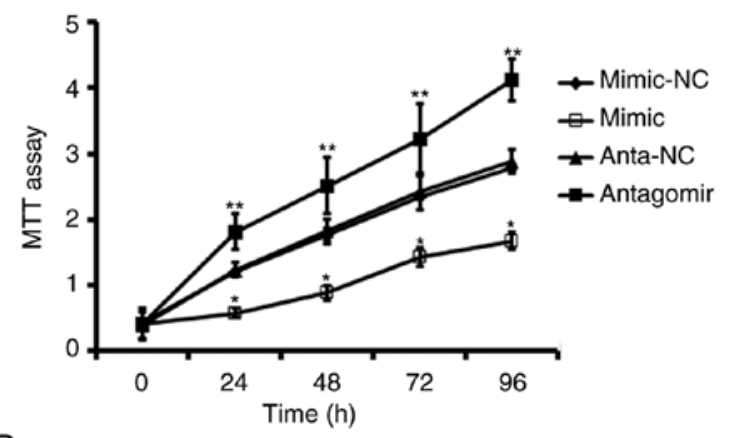

U87MG

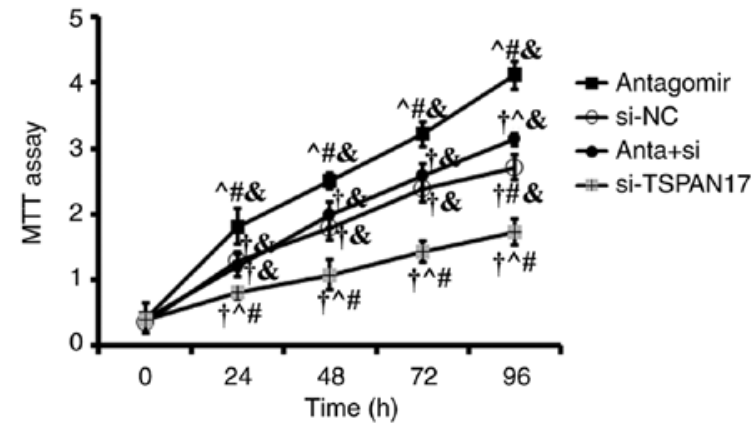

B
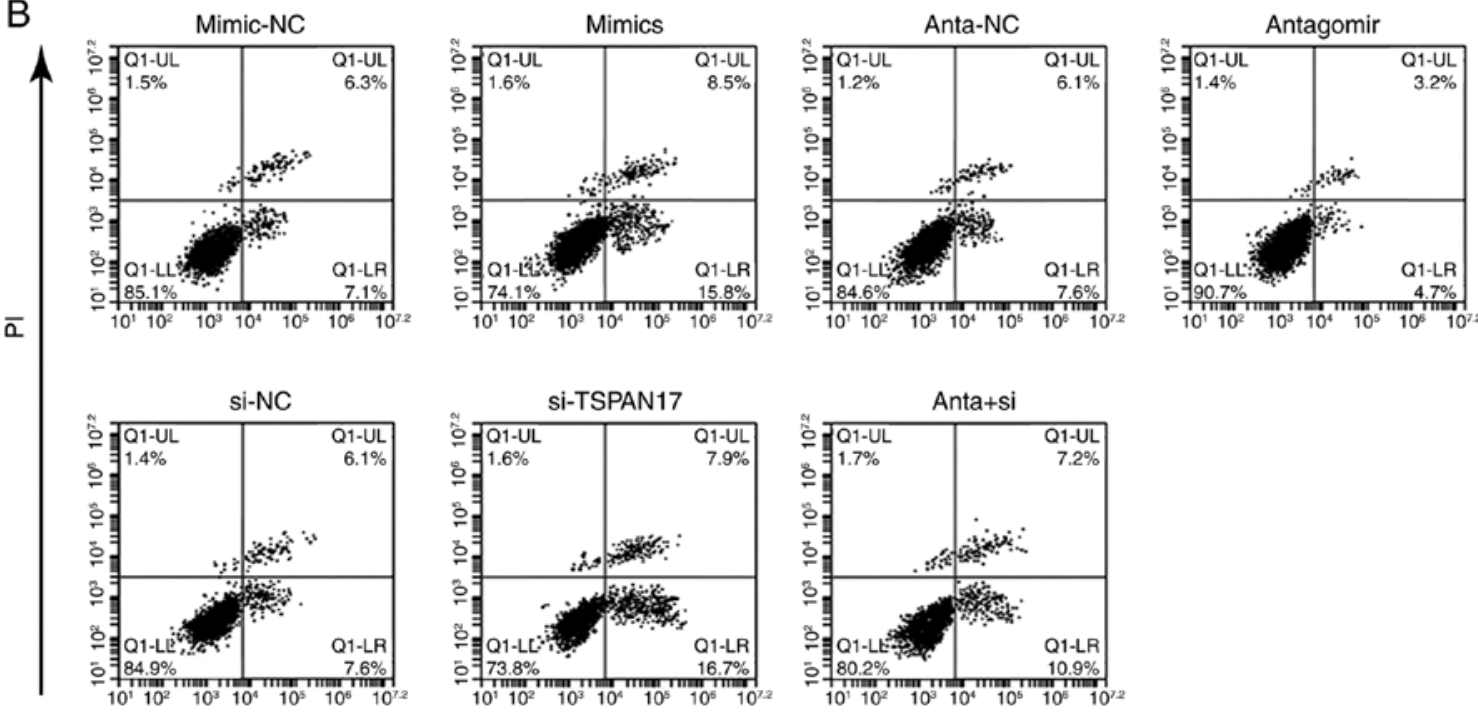

Annexin V-FITC

C

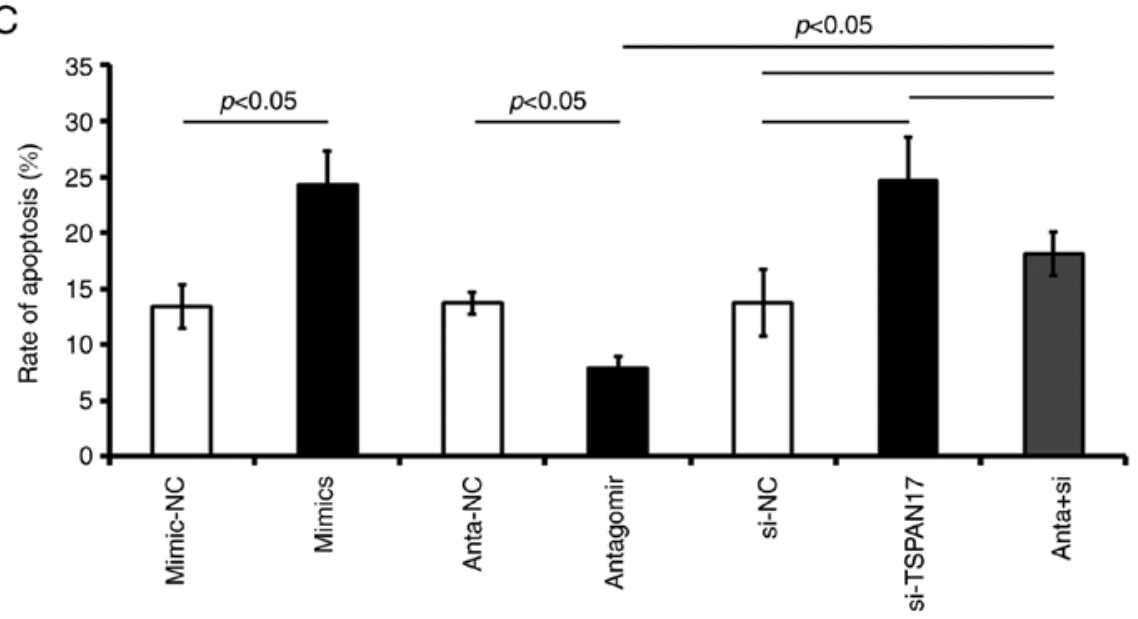

Figure 5. Effects of miR-378a-3p on the proliferation and apoptosis of U87MG cells by targeting TSPAN17. (A) Cell proliferation was analyzed by an MTT assay after transfection; ${ }^{*} \mathrm{P}<0.05$ vs. the mimic-NC control; ${ }^{* *} \mathrm{P}<0.05$ vs. anta-NC; ${ }^{\dagger} \mathrm{P}<0.05$ vs. antagomir; ${ }^{\wedge} \mathrm{P}<0.05$ vs. si-NC; ${ }^{*} \mathrm{P}<0.05$ vs. anta + si; ${ }^{\&} \mathrm{P}<0.05$ vs. si-TSPAN17. (B and C) Apoptosis rates were evaluated by flow cytometry after transfection. Data are presented as mean \pm standard deviation. All the data are representative of five independent experiments $(\mathrm{n}=5)$. FITC, fluorescein isothiocyanate; PI, propidium iodide; miR, microRNA; mimic-NC, miR-378a-3p mimic negative control; mimic, miR-378a-3p mimic; anta-NC, antagomir negative control; anta, antagomir, miR-378a-3p antagomir; si-NC, small interfering RNA negative control; TSPAN17, tetraspanin 17; si-TSPAN17, TSPAN17 small interfering RNA; anta + si, miR-378a-3p antagomir + TSPAN17 small interfering RNA.

\section{Discussion}

The present study showed that miR-378a-3p expression was downregulated in GBM tissues and cell lines, whereas TSPAN17 expression was upregulated. High levels of
miR-378a-3p and low levels of TSPAN17 expression were linked to better survival in patients with GBM. Additionally, high expression levels of TSPAN17 were associated with poor prognosis in patients with GBM aged 50-60 years, tumor size and WHO grade. TSPAN17 was identified and confirmed as a 

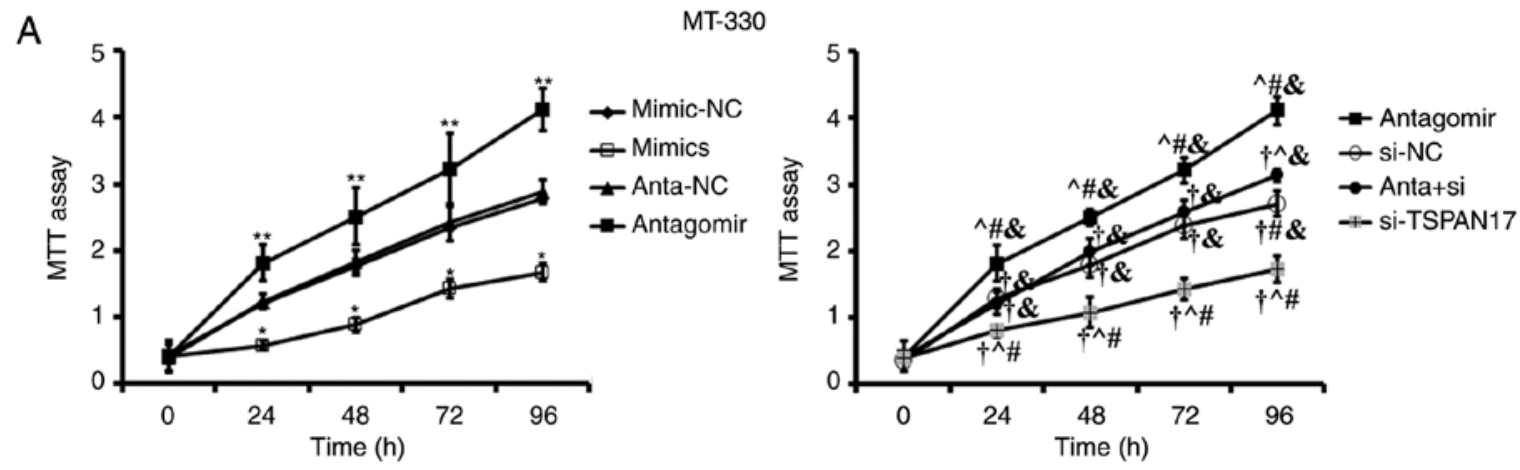

B
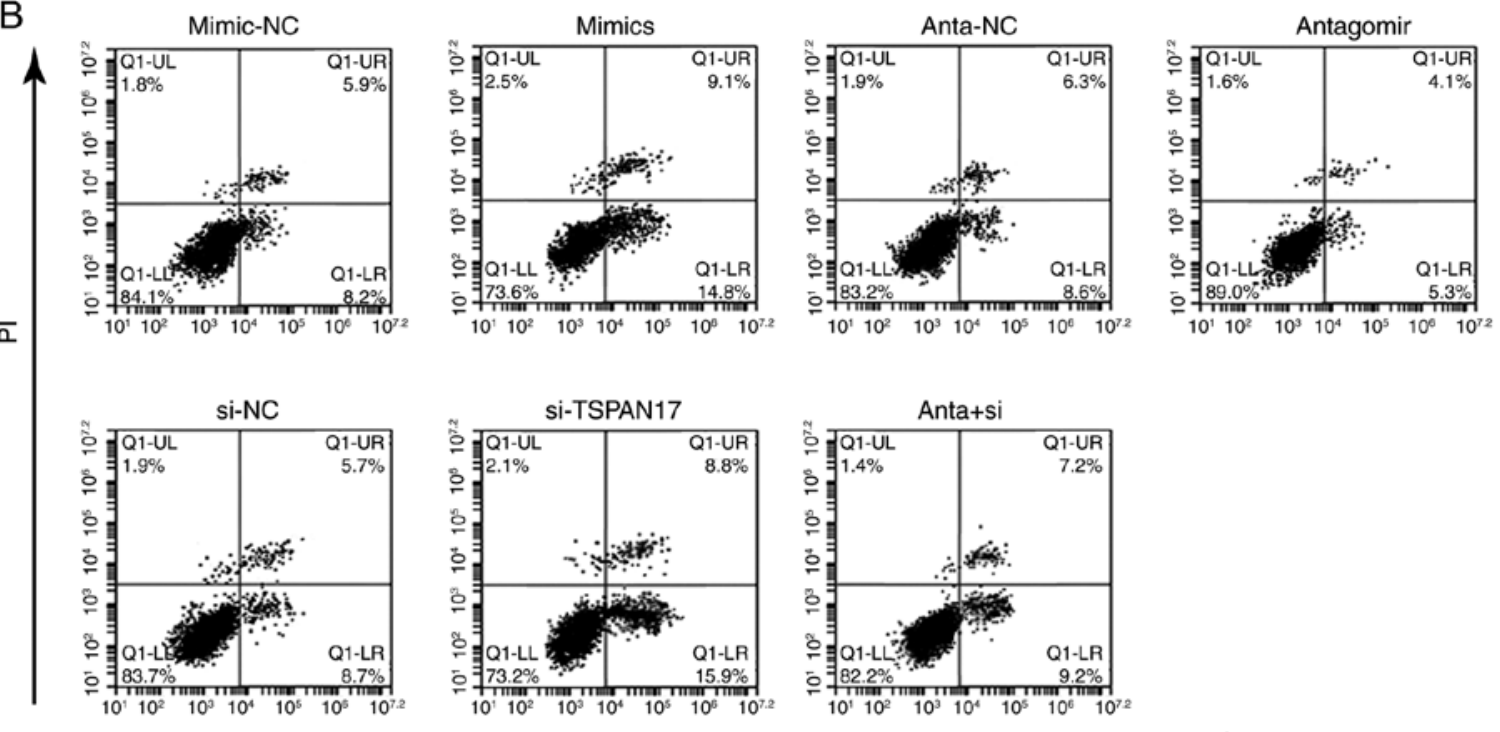

Annexin V-FITC

C

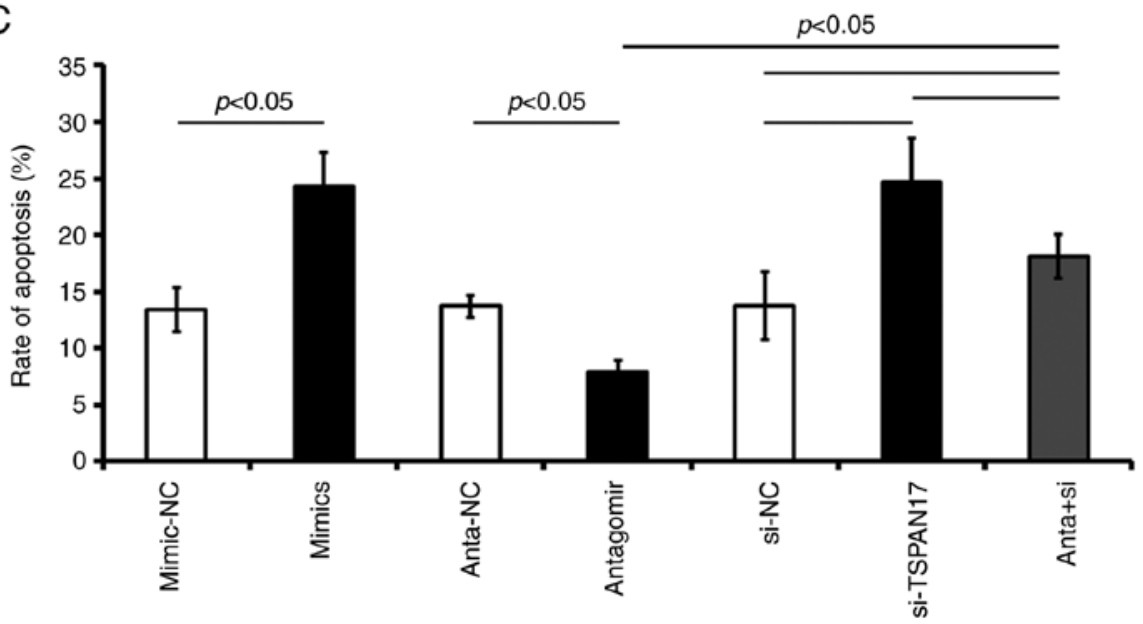

Figure 6. Effects of miR-378a-3p on the proliferation and apoptosis of MT-330 cells by targeting TSPAN17. (A) Cell proliferation was detected by an MTT assay after treatment various reagents. ${ }^{*} \mathrm{P}<0.05$ vs. the mimic-NC control; ${ }^{* *} \mathrm{P}<0.05$ vs. anta- $\mathrm{NC} ;{ }^{\dagger} \mathrm{P}<0.05$ vs. antagomir; ${ }^{\wedge} \mathrm{P}<0.05$ vs. si-NC; ${ }^{*} \mathrm{P}<0.05$ vs anta + si; ${ }^{\&} \mathrm{P}<0.05$ vs. si-TSPAN17. (B and C) Apoptosis rates were evaluated by flow cytometry after transfection. Data are represented as mean \pm standard deviation. All the data are representative of five independent experiments $(\mathrm{n}=5)$. FITC, fluorescein isothiocyanate; PI, propidium iodide; miR, microRNA; mimic-NC, miR-378a-3p mimic negative control; mimic, miR-378a-3p mimic; anta-NC, antagomir negative control; antagomir, miR-378a-3p antagomir; si-NC, small interfering RNA negative control; TSPAN17, tetraspanin 17; si-TSPAN17, small interfering RNA; anta + si, miR-378a-3p antagomir + TSPAN17 small interfering RNA.

direct target of miR-378a-3p using a luciferase reporter assay in human glioma cell lines. Overexpression of miR-378a-3p in both U87MG and MT-330 cells decreased TSPAN17 expression, induced apoptosis, and suppressed proliferation, migration and invasion. Functional inhibition of miR-378a-3p using the antagomir in GBM cells increased TSPAN17 expression levels, reduced apoptosis rates, and promoted proliferation, migration and invasion. Co-treated with the miR-378a-3p antagomir and TSPAN17-siRNA attenuated the effects induced by antagomir transfection alone. These data 

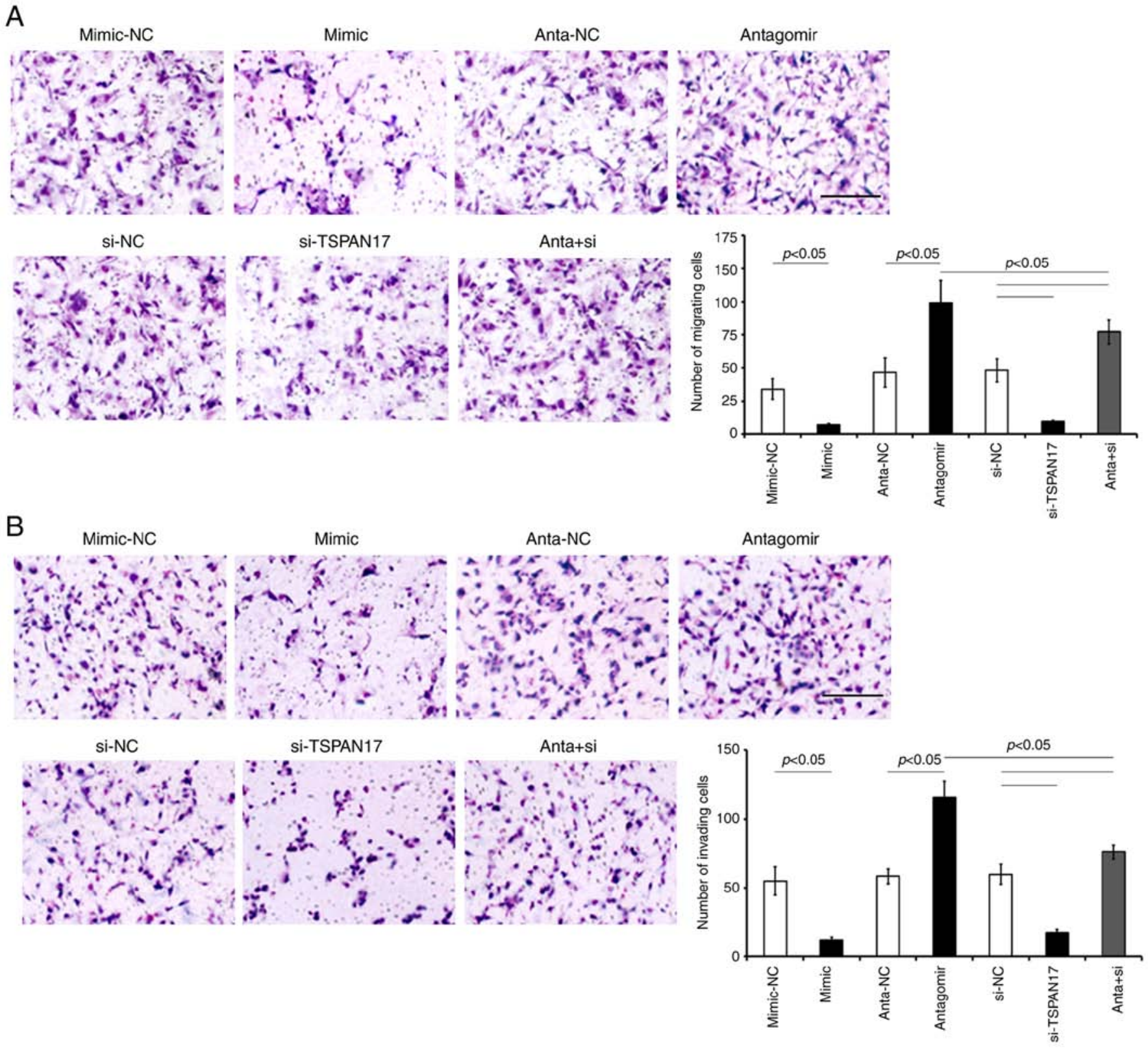

Figure 7. Effects of microRNA-378a-3p on the migration and invasion of U87MG cells by targeting TSPAN17. Analysis of (A) migration and (B) invasion of transfected U87MG cells via crystal violet staining. Data are presented as the mean \pm standard deviation. All the data are representative of five independent experiments $(\mathrm{n}=5)$. Scale bar $=20 \mu \mathrm{m}$. mimic-NC, microRNA-378a-3p mimic negative control; si-NC, small interfering RNA negative control; TSPAN17, tetraspanin 17; si-TSPAN17, small interfering RNA; anta + si, miR-378a-3p antagomir + TSPAN17 small interfering RNA.

suggested that miR-378a-3p acted as a suppressor of GBM by targeting TSPAN17 mRNA.

miR-378a is a small noncoding RNA molecule that can regulate gene expression at the post-transcriptional level. miR-378a-3p, one of two mature strands of miR-378a, originates from the first intron of the peroxisome proliferator-activated receptor-g, coactivator $1 \beta$ gene encoding PGC-1 $\beta$ (27-29). Reports demonstrated that miR-378a-3p regulated skeletal muscle growth and promoted the differentiation of myoblasts through the post-transcriptional downregulation of histone acetylation enzyme 4 (30), and was involved in myotonic dystrophy type-2 (31) and adipogenesis by targeting mitogen-activated protein kinase 1 (32). miR-378a-3p has multiple roles in various pathological diseases by post-transcriptionally modifying its potential targets, including in tuberous sclerosis (33), liver fibrosis (34), breast cancer (35) and colorectal cancer (36). The results of the present study showed that: i) The downregulated expression of miR-378a-3p in carcinoma of patients with GBM and in GBM cells; and ii) high miR-378a-3p levels were associated with better survival in patients with GBM. Similar observations have been demonstrated in other studies, which support the hypothesis that miR-378a-3p may function as a tumor suppressor in GBM $(37,38)$.

Subsequently, it was identified and confirmed that TSPAN17 was a direct target of miR-378a-3p, which was associated with a poor prognosis in patients with GBM aged 50-60 years. Overexpression of miR-378a-3p in either the U87MG or MT-330 cells inhibited TSPAN17 expression, induced apoptosis, and suppressed proliferation, migration 
A
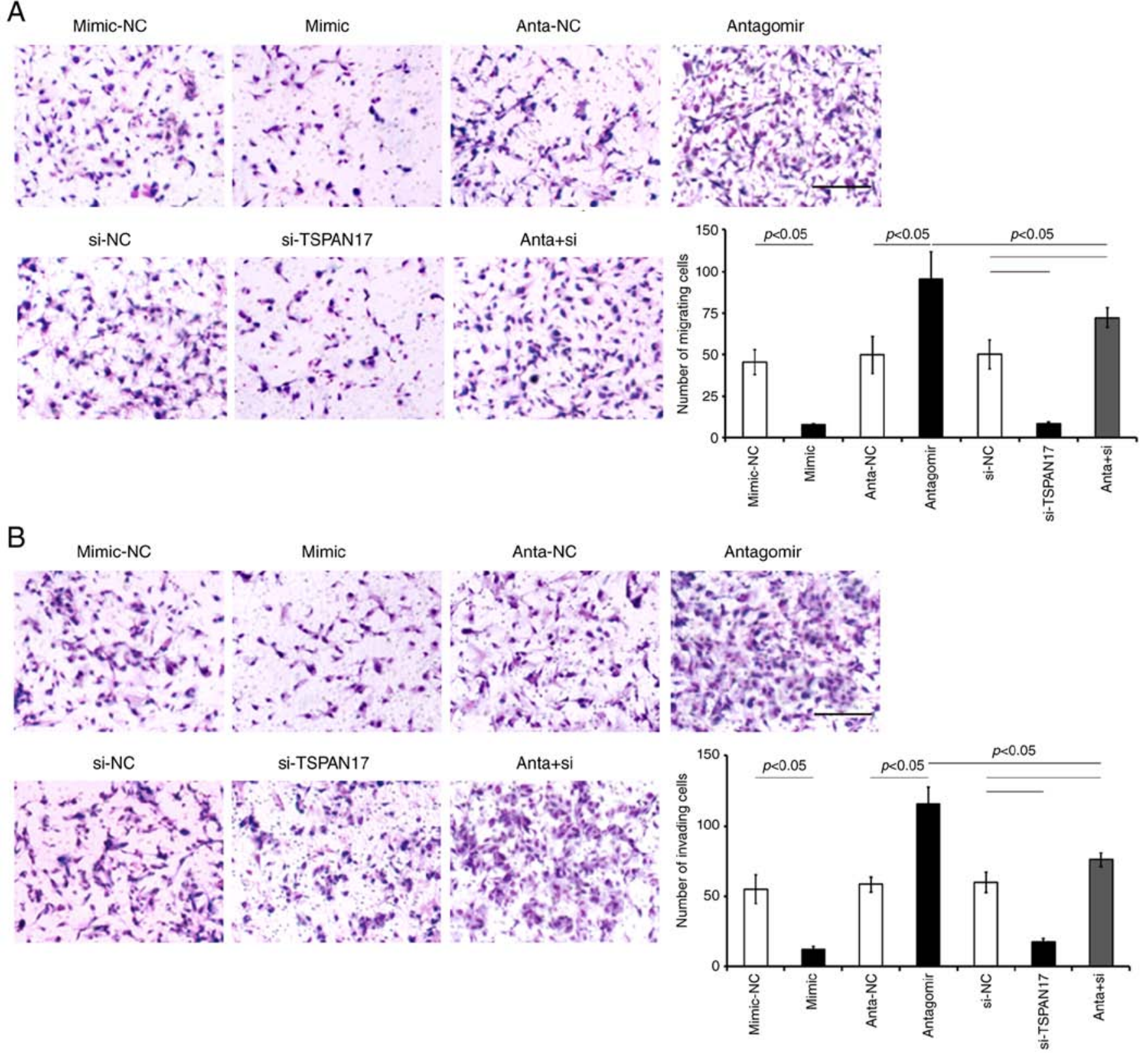

Figure 8. Effects of microRNA-378a-3p on the migration and invasion of MT-330 cells by targeting TSPAN17. Analysis of (A) migration and (B) invasion of transfected MT-330 cells via crystal violet staining. Data are presented as the mean \pm standard deviation. All the data are representative of five independent experiments $(\mathrm{n}=5)$. Scale bar $=20 \mathrm{~mm}$.mimic-NC, microRNA-378a-3p mimic negative control; si-NC, small interfering RNA negative control; TSPAN17, tetraspanin 17; si-TSPAN17, small interfering RNA; anta + si, miR-378a-3p antagomir + TSPAN17 small interfering RNA.

and invasion. Functional inhibition of miR-378a-3p using the antagomir in GBM cells increased the expression levels of TSPAN17, reduced apoptosis rates, and promoted migration and invasion. These data suggest that miR-378a-3p may function as a tumor suppressor in GBM by targeting TSPAN17.

Tetraspanins are a heterogeneous group of four-transmembrane proteins that segregate into tetraspanin-enriched micro domains (TEMs), which interact laterally with each other and different partners, such as integrins, immunoglobulin-domain-containing proteins, growth factors and cytokine receptors (39). TEMs of various types are reportedly involved in the regulation of cell growth, migration and invasion of several tumor cell types, both as suppressors and supporting structures (40). Other members of the tetraspanin family, such as Tspan9, Tspan1 and Tspan5, were demonstrated to serve possible roles in pathophysiological processes and cancer biology, which highlight their contribution to tumorigenesis (41-44). Using co-immunoprecipitation, it has been demonstrated that A disintegrin and metalloprotease 10 (ADAM10) interacted with TSPAN17, which defined TspanC8 tetraspanins as essential regulators of ADAM10 maturation and trafficking to the cell surface (45). However, the role of TSPAN17 in gliomas has not been demonstrated previously, to the best of our knowledge. The present study illustrated the novel roles of miR-378a-3p in regulating TSPAN17 expression and thus its involvement in GBM.

Considering that upregulated TSPAN17 expression in GBM tissues and cell lines was associated with the poor prognosis of patients and malignant features of GBM cells, we proposed 
that TSPAN17 upregulation in normal cell lines might greatly increase the risk of glioma oncogenesis and development. However, further in vivo evaluation is necessary to validate the results obtained from this study. For example, a glioma xenograft nude mouse model could be developed by intradermal injection with TSPAN17 overexpressed/downregulated HF cells or glioma cells in the future. After seeding the tumor cells, tumor growth, and mouse survival may be measured to further confirm the potential effects of TSPAN17 in tumorigenesis of GBM. Additionally, as of the relatively small sample size $(n=53)$ employed in this study, external validation is required in further investigation. We should use public datasets, taking The Cancer Genome Atlas GBM as an example, to examine any consistencies or variations from the results of our study.

In conclusion, in the present study, it was demonstrated that: i) Upregulation of TSPAN17 was associated with a poor prognosis in patients with GBM aged 50-60 years; ii) TSPAN17 was identified and confirmed as a direct target of miR-378a-3p by a luciferase report assay; and iii) overexpression of miR-378a-3p in both U87MG and MT-330 cells inhibited TSPAN17 expression, induced apoptosis and suppressed proliferation, migration and invasion, and functional inhibition of miR-378a-3p by antagomir reversed these effects. TSPAN17-siRNA transfection also reversed the effects induced by miR-378a-3p antagomir transfection in GBM cells. The results highlight the potential role of miR-378a-3p as a suppressor of GBM by targeting TSPAN17.

\section{Acknowledgements}

We thank Doctor Jing Wu for his valuable work in tumor specimen collection.

\section{Funding}

The present study was supported by the National Natural Science Foundation of China (grant nos. 81660613, 81160401, 81260493 and 30660212); the Natural Science Foundation of Yunnan Province (grant nos. 2008CC009, 2013FB103 and 2015FA021); the Joint Special Funds for the Department of Science and Technology of Yunnan Province-Kunming Medical University (grant no. K13201234); and the Science Foundation of Yun-nan Provincial Education Bureau (grant no. 2015 Y154 and 2017zDX164).

\section{Availability of data and materials}

The datasets used and analyzed in the present study are available from the corresponding author on reasonable request.

\section{Authors' contributions}

$\mathrm{XBG}, \mathrm{ZQS}$, and $\mathrm{XCZ}$ designed this study and wrote the manuscript. LMM, XBG, ZQS, and XCZ conducted the statistical analysis. $\mathrm{PC}$ and $\mathrm{XCZ}$ performed tumor tissues preparation and cell culture. XBG, ZQS, PC and LMM performed cell experiments, RT-qPCR, the luciferase reporter assay and western blotting. XBG, XCZ and ZQS performed the MTT assay and flow cytometry analysis. PC and LMM performed the migration and invasion assays. All authors have read and approved the final manuscript.

\section{Ethics approval and consent to participate}

All procedures performed in studies involving human participants were in accordance with the 1964 Helsinki declaration and its later amendments or comparable ethical standards. This study was approved by The Medical Ethics Committee of Kunming Medical University (Kunming, China). GBM tumor specimens were obtained from patients at The First People's Hospital of Yunnan Province (Yunnan, China) who provided written informed consent.

\section{Patient consent for publication}

Not applicable.

\section{Competing interests}

The authors declare that they have no acompeting interests.

\section{References}

1. Fisher JL, Schwartzbaum JA, Wrensch M and Wiemels JL: Epidemiology of brain tumors. Neurol Clin 25: 867-890, 2007.

2. Bondy ML, Scheurer ME, Malmer B, Barnholtz-Sloan JS, Davis FG, Il'yasova D, Kruchko C, McCarthy BJ, Rajaraman P, Schwartzbaum JA, et al: Brain tumor epidemiology: Consensus from the brain tumor epidemiology consortium. Cancer 113 (Suppl 7): S1953-S1968, 2008.

3. Feng J, Kim ST, Liu W, Kim JW, Zhang Z, Zhu Y, Berens M, Sun J and $\mathrm{Xu} \mathrm{J}$ : An integrated analysis of germline and somatic, genetic and epigenetic alterations at $9 \mathrm{p} 21.3$ in glioblastoma. Cancer 118: 232-240, 2012.

4. Ambros V: The functions of animal microRNAs. Nature 431: 350-355, 2004.

5. Caserta S, Kern F, Cohen J, Drage S, Newbury SF and Llewelyn MJ: Circulating plasma microRNAs can differentiate human sepsis and systemic inflammatory response syndrome (SIRS). Sci Rep 6: 28006, 2016.

6. McClure C, McPeak MB, Youssef D, Yao ZQ, McCall CE and El Gazzar M: Stat 3 and C/EBP $\beta$ synergize to induce miR-21 and miR-181b expression during sepsis. Immunol Cell Biol 95: 42-55, 2017.

7. Rolle K: miRNA Multiplayers in glioma: From bench to bedside. Acta Biochim Pol 62: 353-365, 2015.

8. Browne G, Dragon JA, Hong D, Messier TL, Gordon JA Farina NH, Boyd JR, VanOudenhove JJ,Perez AW, Zaidi SK, et al: MicroRNA-378-mediated suppression of Runx1 alleviates the aggressive phenotype of triple-negative MDA-MB-231 human breast cancer cells. Tumour Biol 37: 8825-8839, 2016.

9. Mirzaei H, Khataminfar S, Mohammadparast S, Sales SS, Maftouh M, Mohammadi M, Simonian M, Parizadeh SM, Hassanian SM and Avan A: Circulating microRNAs as potential diagnostic biomarkers and therapeutic targets in gastric cancer: Current status and future perspectives. Curr Med Chem 23: 4135-4150, 2016.

10. Peng J, Xie Z, Cheng L, Zhang Y, Chen J, Yu H, Li Z and Kang H: Paired design study by real-time PCR: miR-378* and miR-145 are potent early diagnostic biomarkers of human colorectal cancer. BMC Cancer 15: 158, 2015.

11. Scapoli L, Palmieri A, Lo Muzio L, Pezzetti F, Rubini C, Girardi A, Farinella F, Mazzotta M and Carinci F: MicroRNA expression profiling of oral carcinoma identifies new markers of tumor progression. Int J Immunopathol Pharmacol 23: 1229-1234, 2010.

12. Zhu XW, Wen XM, Zhang YY, Yang L, Guo H, Yang J, Zhang M, Yin JY, Ma JC, Lin J, et al: The 5'flanking region of miR-378 is hypomethylated in acute myeloid leukemia. Int J Clin Exp Pathol 8: 4321-4331, 2015. 
13. Li B, Wang Y, Li S, He H, Sun F, Wang C, Lu Y, Wang X and Tao B: Decreased expression of miR-378 correlates with tumor invasiveness and poor prognosis of patients with glioma. Int J Clin Exp Pathol 8: 7016-7021, 2015.

14. Arita H, Yamasaki K, Matsushita Y, Nakamura T, Shimokawa A, Takami H, Tanaka S, Mukasa A, Shirahata M, Shimizu S, et al: A combination of TERT promoter mutation and MGMT methylation status predicts clinically relevant subgroups of newly diagnosed glioblastomas. Acta Neuropathol Commun 4: 79, 2016

15. Turkalp Z, Karamchandani J and Das S: IDH mutation in glioma: New insights and promises for the future. JAMA Neurol 71: 1319-1325, 2014.

16. Mulholland S, Pearson DM, Hamoudi RA, Malley DS, Smith CM, Weaver JM, Jones DT, Kocialkowski S, Bäcklund LM, Collins VP and Ichimura K: MGMT CpG island is invariably methylated in adult astrocytic and oligodendroglial tumors with IDH1 or IDH2 mutations. Int J Cancer 131: 1104-1113, 2012.

17. Okita Y, Narita Y, Miyakita Y, Ohno M, Matsushita Y, Fukushima S, Sumi M, Ichimura K, Kayama T and Shibui S: IDH1/2 mutation is a prognostic marker for survival and predicts response to chemotherapy for grade II gliomas concomitantly treated with radiation therapy. Int J Oncol 41: 1325-1336, 2012.

18. Arita H, Narita Y, Matsushita Y, Fukushima S, Yoshida A, Takami H, Miyakita Y, Ohno M, Shibui S and Ichimura K: Development of a robust and sensitive pyrosequencing assay for the detection of IDH1/2 mutations in gliomas. Brain Tumor Pathol 32: 22-30, 2015.

19. Arita H, Narita Y, Fukushima S, Tateishi K, Matsushita Y, Yoshida A, Miyakita Y, Ohno M, Collins VP, Kawahara N, et al: Upregulating mutations in the TERT promoter commonly occur in adult malignant gliomas and are strongly associated with total 1p19q loss. Acta Neuropathol 126: 267-276, 2013.

20. Livak KJ and Schmittgen TD: Analysis of relative gene expression data using real-time quantitative PCR and the 2(-Delta Delta C(T)) method. Methods 25: 402-408, 2001.

21. Skup M, Dwornik A, Macias M, Sulejczak D, Wiater M and Czarkowska-Bauch J: Long-term locomotor training upregulates TrkBFL receptor-like proteins, brain-derived neurotrophic factor, and neurotrophin 4 with different topographies of expression in oligodendroglia and neurons in the spinal cord. Exp Neurol 176 289-307, 2002

22. Minemura $H$, Takagi K, Miki Y, Shibahara Y, Nakagawa S, Ebata A, Watanabe M, Ishida T, Sasano $H$ and Suzuki T: Abnormal expression of miR-1 in breast carcinoma as a potent prognostic factor. Cancer Sci 106: 1642-1650, 2015.

23. Hu T, Li YS, Chen B, Chang YF, Liu GC, Hong Y, Chen HL and Xiyang YB: Elevated glucose-6-phosphate dehydrogenase expression in the cervical cancer cases is associated with the cancerigenic event of high-risk human papillomaviruses. Exp Biol Med (Maywood) 240: 1287-1297, 2015.

24. Liang L, Wong CM, Ying Q, Fan DN, Huang S, Ding J, Yao J, Yan M, Li J, Yao M, et al: MicroRNA-125b suppressed human liver cancer cell proliferation and metastasis by directly targeting oncogene LIN28B2. Hepatology 52: 1731-1740, 2010.

25. He Z, Xia Y, Liu B, Qi X, Li Z, Wang J, Chen L and Chen Y: Down-regulation of miR-452 is associated with poor prognosis in the non-small-cell lung cancer. J Thorac Dis 8: 894-900, 2016.

26. Li Z, Piao YS, Zhang LY, Wang LM, Wang DD, Fu YJ, Cai YN and Lu DH: Application of ATRX in diagnosis and prognostic evaluation of glioma. Zhonghua Bing Li Xue Za Zhi 46: 690-694, 2017 (In Chinese)

27. Krist B, Florczyk U, Pietraszek-Gremplewicz K, Józkowicz A and Dulak J: The role of miR-378a in metabolism, angiogenesis, and muscle biology. Int J Endocrinol 2015: 281756, 2015.

28. Eichner LJ, Perry MC, Dufour CR, Bertos N, Park M, St-Pierre J and Giguère V: miR-378(*) mediates metabolic shift in breast cancer cells via the PGC-1 $\beta /$ ERR $\gamma$ transcriptional pathway. Cell Metab 12: 352-361, 2010.

29. Kasashima K, Nakamura Y and Kozu T: Altered expression profiles of microRNAs during TPA-induced differentiation of HL-60 cells. Biochem Biophys Res Commun 322: 403-410, 2004.
30. Wei X, Li H, Zhang B, Li C, Dong D, Lan X, Huang Y, Bai Y, Lin F, Zhao X and Chen H: miR-378a-3p promotes differentiation and inhibits proliferation of myoblasts by targeting HDAC4 in skeletal muscle development. RNA Biol 13: 1300-1309, 2016

31. Greco S, Perfetti A, Fasanaro P, Cardani R, Capogrossi MC, Meola G and Martelli F: Deregulated microRNAs in myotonic dystrophy type 2. PLoS One 7: e39732, 2012.

32. Huang N, Wang J, Xie W, Lyu Q, Wu J, He J, Qiu W, Xu N and Zhang Y: miR-378a-3p enhances adipogenesis by targeting mitogen-activated protein kinase 1 . Biochem Biophys Res Commun 457: 37-42, 2015.

33. Trelinska J, Fendler W, Dachowska I, Kotulska K, Jozwiak S, Antosik K, Gnys P, Borowiec M and Mlynarski W: Abnormal serum microRNA profiles in tuberous sclerosis are normalized during treatment with everolimus: Possible clinical implications. Orphanet J Rare Dis 11: 129, 2016.

34. Hyun J, Wang S, Kim J, Rao KM, Park SY, Chung I, Ha CS, Kim SW, Yun YH and Jung Y: MicroRNA-378 limits activation of hepatic stellate cells and liver fibrosis by suppressing Gli3 expression. Nat Commun 7: 10993, 2016.

35. Ikeda K, Horie-Inoue K, Ueno T, Suzuki T, Sato W, Shigekawa T, Osaki A, Saeki T, Berezikov E, Mano H and Inoue S: miR-378a-3p modulates tamoxifen sensitivity in breast cancer MCF-7 cells through targeting GOLT1A. Sci Rep 5: 13170, 2015.

36. Kara M, Yumrutas O, Ozcan O, Celik OI, Bozgeyik E, Bozgeyik I and Tasdemir S: Differential expressions of cancer-associated genes and their regulatory miRNAs in colorectal carcinoma. Gene 567: 81-86, 2015.

37. Megiorni F, Cialfi S, McDowell HP, Felsani A, Camero S, Guffanti A, Pizer B, Clerico A, De Grazia A, Pizzuti A, et al: Deep sequencing the microRNA profile in rhabdomyosarcoma reveals down-regulation of miR-378 family members. BMC Cancer 14: 880, 2014.

38. Li H, Dai S, Zhen T, Shi H, Zhang F, Yang Y, Kang L, Liang Y and Han A: Clinical and biological significance of miR-378a-3p and miR-378a-5p in colorectal cancer. Eur J Cancer 50: 1207-1221, 2014.

39. Masse I, Agaësse G and Berthier-Vergnes O: Tetraspanins in cutaneous physiopathology. Med Sci (Paris) 32: 267-273, 2016 (In French).

40. Hölters S, Anacker J, Jansen L, Beer-Grondke K, Dürst M and Rubio I: Tetraspanin 1 promotes invasiveness of cervical cancer cells. Int J Oncol 43: 503-512, 2013.

41. He P, Wang S, Zhang X, Gao Y, Niu W, Dong N, Shi X, Geng Y, Ma Q, Li M, et al: Tspan5 is an independent favourable prognostic factor and suppresses tumour growth in gastriccancer. Oncotarget 7: 40160-40173, 2016.

42. Yang YG, Sari IN, Zia MF, Lee SR, Song SJ and Kwon HY: Tetraspanins: Spanning from solid tumors to hematologic malignancies. Exp Hematol 44: 322-338, 2016.

43. Wang XF, Gao GD, Liu J, Guo R, Lin YX, Chu YL, Han FC, Zhang WH and Bai YJ: Identification of differentially expressed genes induced by angiotensin II in rat cardiac fibroblasts. Clin Exp Pharmacol Physiol 33: 41-46, 2006.

44. Hou FQ, Lei XF, Yao JL, Wang YJ and Zhang W: Tetraspanin 1 is involved in survival, proliferation and carcinogenesis of pancreatic cancer. Oncol Rep 34: 3068-3076, 2015.

45. Haining EJ, Yang J, Bailey RL, Khan K, Collier R, Tsai S, Watson SP, Frampton J, Garcia P and Tomlinson MG: The TspanC8 subgroup of tetraspanins interacts with A disintegrin and metalloprotease 10 (ADAM10) and regulates its maturation and cell surface expression. J Biol Chem 287: 39753-39765, 2012.

46. Zhang YA, Zhou Y, Luo X, Song K, Ma X, Sathe A, Girard L, Xiao G and Gazdar AF: SHOX2 is a potent independent biomarker to predict survival of WHO grade II-III diffuse gliomas. EBioMedicine 13: 80-89, 2016.

This work is licensed under a Creative Commons Attribution-NonCommercial-NoDerivatives 4.0 International (CC BY-NC-ND 4.0) License. 